\title{
A Multiyear Analysis of Global Precipitation Combining CloudSat and GPM Precipitation Retrievals
}

\author{
LINDSEY HAYDEN AND CHUNTAO LIU \\ Department of Physical and Environmental Sciences, Texas A\&M University at Corpus Christi, Corpus Christi, Texas
}

(Manuscript received 20 March 2018, in final form 30 October 2018)

\begin{abstract}
Satellite-based instruments are essential to the observation of precipitation at a global scale, especially over remote regions. Each instrument has its own strengths and limitations in accurately determining the rate of precipitation at the surface. By using the complementary strengths of two instruments, a more complete analysis of global precipitation can be performed. The Global Precipitation Measurement (GPM) Core Observatory's Dual-Frequency Precipitation Radar (DPR) is capable of measuring precipitation at high and medium precipitation rates by using Ku-band $(13.6 \mathrm{GHz})$ radiation. The CloudSat satellite's Cloud Profiling Radar (CPR) uses higher-frequency W-band $(94 \mathrm{GHz})$ radiation and is therefore capable of measuring precipitation at low rates not detected by the GPM DPR. CloudSat observations from January 2007 to December 2016 and DPR observations from March 2014 to February 2018 are combined and the results examined. Since these datasets are not completely coincident, this study is conducted as a multiyear analysis. Observed precipitation from CloudSat is used starting at the lowest precipitation rates and increasing rates until the occurrence observed by GPM surpasses that of CloudSat, at which point data from GPM are used. The precipitation rate at which this change occurs contains important information on the amount of precipitation missed by each instrument and implications as to the size of the hydrometeors present. Liquid precipitation retrieval from CloudSat is not performed over land; analysis over land is produced here using the information available. By combining the two datasets, a more complete picture of precipitation occurring globally is obtained.
\end{abstract}

\section{Introduction}

Precipitation is an integral part of the Earth-atmospherebiosphere system. An accurate description of precipitation on a global scale is necessary for the assessment and calibration of global climate and weather forecasting models, as well as global energy budget and water resource calculations (e.g., Xie and Arkin 1997; Adler et al. 2003; Huffman et al. 2007, 2009; Wood 2012). It is therefore important to produce an accurate record of the geographical and temporal distribution of precipitation events. Satellite-based instruments, particularly active sensors, such as on board the Tropical Rainfall Measuring Mission (TRMM; Kummerow et al. 1998) and CloudSat (Stephens et al. 2008) satellites, are well suited to this task. The measurement capabilities of individual instruments, however, are limited by the frequency of the radiation they use. Instruments using relatively high-frequency radiation are sensitive to light precipitation

Corresponding author: Lindsey Hayden, lhayden@islander. tamucc.edu
(Lebsock and L'Ecuyer 2011). This sensitivity makes them unable to accurately measure moderate and heavy precipitation, however, as the signal is quickly fully attenuated. Longer-wavelength instruments have an opposite problem; they can observe moderate to heavy precipitation events, but are unable to fully detect lighter events (Berg et al. 2010). Since these types of measurements are complementary, a rainfall climatology produced using both should be more complete than one produced by a single instrument (Behrangi et al. 2012).

Several studies (Berg et al. 2010; Behrangi et al. 2012) have previously combined precipitation measurements from spaceborne instruments, such as the TRMM Precipitation Radar (PR) and the CloudSat Cloud Profiling Radar (CPR). These studies combine PR and CPR data into a single database, using CPR data for light rain rates $\left(<1 \mathrm{~mm} \mathrm{~h}^{-1}\right)$ and $\mathrm{PR}$ data for heavier rain rates $\left(>2 \mathrm{~mm} \mathrm{~h}^{-1}\right)$, scaling the amount of rain for rain rates between the two thresholds to be the same from both sensors (Berg et al. 2010). Both studies found an underestimation of light rain rates by the PR and underestimation of heavier rain rates by the CPR. The study by Berg et al. (2010) was 
limited to the tropics and subtropics, while Behrangi et al. (2012) extended to the mid- and high latitudes by incorporating passive microwave and infrared observations of precipitation in combination with the CloudSat data. This study aims to produce a similar dataset, improving on previous studies by extending the use of active precipitation measurements to the mid- and high latitudes for all precipitation rates, including frozen precipitation in the analysis, utilizing observations over land, and increasing the spatial and temporal resolution of the analysis.

The Global Precipitation Measurement (GPM; Hou et al. 2014; Skofronick-Jackson et al. 2017) mission's core satellite carries two instruments designed to measure precipitation: the GPM Microwave Imager (GMI) and the Dual-Frequency Precipitation Radar (DPR). The DPR aims to measure moderate to heavy precipitation $\left(>0.5 \mathrm{~mm} \mathrm{~h}^{-1}\right)$ with a Ka-band $(35.5 \mathrm{GHz})$ radar (KaPR) and a Ku-band (13.6 GHz) radar (KuPR; Seto et al. 2013). Only measurements from the KuPR were used in this study, however, because of the wider swath and increased capability to measure heavy precipitation. The minimum detectable reflectivity of the DPR is $\sim 12 \mathrm{dBZ}$, corresponding to a minimum detectable precipitation rate of $0.15 \mathrm{~mm} \mathrm{~h}^{-1}$ (Hamada and Takayabu 2016). Complementary to the KuPR measurements, light precipitation measurements are made by the CPR on board the CloudSat satellite. The CPR is a W-band $(94 \mathrm{GHz})$ radar originally designed to measure cloud properties and has a minimum detectable reflectivity of $-28 \mathrm{dBZ}$ (Kulie et al. 2016). This allows the CPR to detect light precipitation and the onset of precipitation events, but makes it highly susceptible to attenuation and multiple scattering effects. Haynes et al. (2009) determined that multiple scattering effects are large and must be taken into account for CPR measurements of precipitation rates greater than $3 \mathrm{~mm} \mathrm{~h}^{-1}$. When used in combination, the CPR and DPR can measure precipitation rates ranging from 0.01 to $300 \mathrm{~mm} \mathrm{~h}^{-1}$. This represents a nearly complete spectrum of precipitation rates. The work presented here proposes a method for combining the observations from these two instruments. With this method, a multiyear analysis of global precipitation consisting of a full precipitation rate spectrum is built. Further, we try to understand the regional variations of different precipitation detectability between the two instruments. The multiyear analysis presented here is similar to a climatology in many respects and, for convenience, will hereafter be described as such, despite the lack of a long time span used to produce a traditional climatology.

A description of the data used is presented in section 2, along with the methodology. Section 3 gives an overview of the features of the resulting dataset. A comparison with data from the Global Precipitation Climatology Project (GPCP; Huffman et al. 1997) as well as some sources of error included in the combined dataset is presented in section 4 , while section 5 gives a short summary and conclusions.

\section{Data and methods}

\section{a. Data}

Two satellite datasets are used in this study, the precipitation retrieval using KuPR data from the GPM satellite, and the precipitation estimates using the CPR data from the CloudSat satellite. The GPM satellite orbits at an altitude of $407 \mathrm{~km}$ at an inclination of $65^{\circ}$. The KuPR has a pixel size of about $5 \mathrm{~km}$ in diameter and a swath width of $245 \mathrm{~km}$ (Seto et al. 2013). This gives the sensor a ground track repeat time of approximately 2 days and allows for measurements between $65^{\circ} \mathrm{N}$ and $65^{\circ} \mathrm{S}$. The KuPR precipitation retrieval algorithm uses a Hitschfeld-Bordan attenuation correction algorithm (Hitschfeld and Bordan 1954) as well as the Surface Reference Technique (SRT; Iguchi et al. 2017) to adjust the measured reflectivity to account for attenuation (Seto et al. 2013; Iguchi et al. 2017). Precipitation rate is then calculated using the attenuationcorrected reflectivity, in addition to a relationship between the precipitation rate $R$ and the mass weighted mean diameter $D_{m}$. The path integrated attenuation (PIA) is calculated using this $R-D_{m}$ relationship and compared to the PIA obtained using the SRT. The $R-D_{m}$ relationship is then adjusted to better match the SRT PIA. A more detailed description of the algorithm can be found in Iguchi et al. (2017). The GPM core satellite was launched on 27 February 2014. The GPM data used in this study are the near-surface precipitation retrieval in the version 5 2AKu radar product from March 2014 through February 2018, representing 4 full years of data from the GPM KuPR. These data can be retrieved from https://pmm. nasa.gov/data-access/downloads/gpm. The 4-yr average daily precipitation rate for these KuPR data over the study region, $65^{\circ} \mathrm{N}-65^{\circ} \mathrm{S}$, is shown in Fig. 1a. Many large-scale features can easily be seen, including the intertropical convergence zone (ITCZ), heavy precipitation over the Maritime Continent, and midlatitude storm track regions, especially off the east coast of North America. The GPM satellite captures the expected distribution of precipitation reasonably well.

CloudSat was launched as part of the A-Train constellation of satellites on 1 June 2006. It orbits at an altitude of $705 \mathrm{~km}$ in a sun-synchronous, near-polar orbit. The CPR has a footprint size of $1.4 \times 1.7 \mathrm{~km}^{2}$ and is a nadir-pointing radar. This allows precipitation measurements to be made from $82.5^{\circ} \mathrm{N}$ to $82.5^{\circ} \mathrm{S}$ and have a ground 


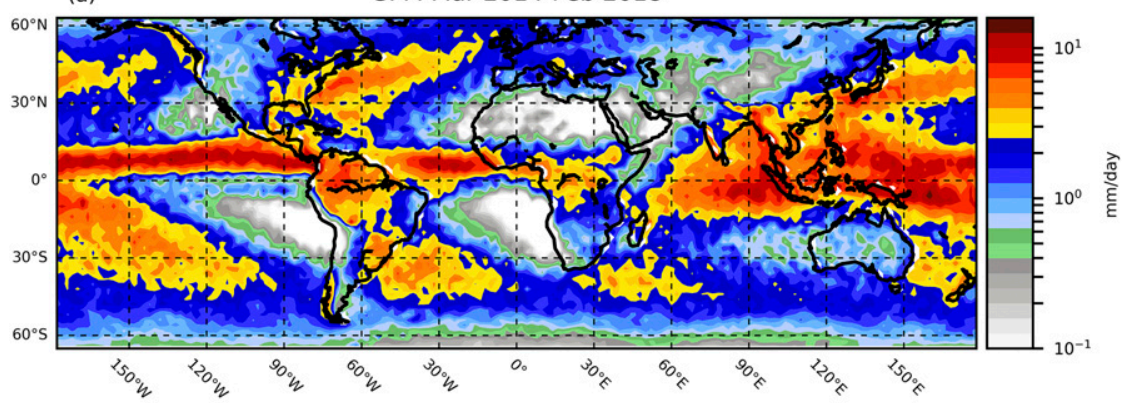

(b)

CloudSat Jan 2007-Dec 2016

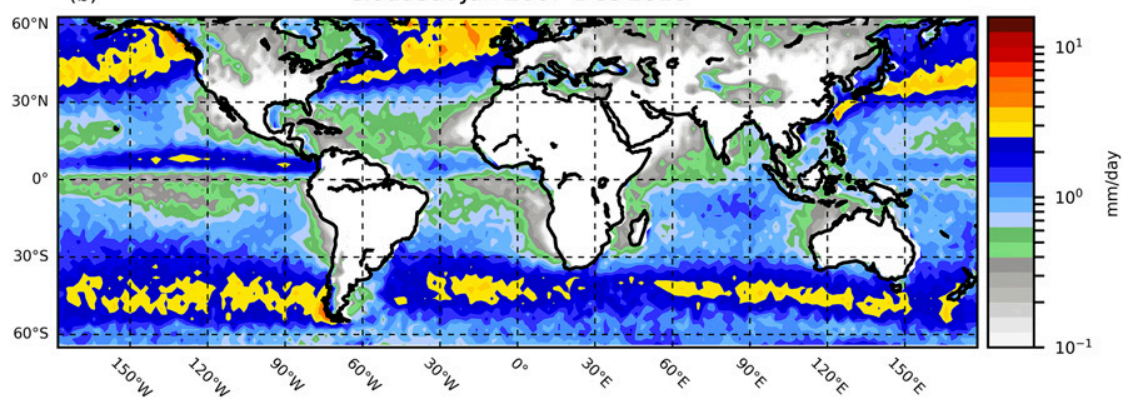

FIG. 1. Daily average precipitation as observed by (a) GPM KuPR and (b) CloudSat CPR.

track repeat time of approximately 16 days. The sun-synchronous orbit results in measurements being made twice per day, at the same local solar time, near 0130 and 1330 LT each day. This results in a diurnal sampling bias in the CloudSat data. Two different algorithms are employed to retrieve both liquid and solid precipitation from CloudSat measurements. The CPR 2C-PRECIP-COLUMN algorithm is used here for liquid precipitation. This algorithm estimates the PIA from an estimate of the surface backscatter (Haynes et al. 2009). Ocean surface backscatter is calculated from the surface wind speed and sea surface temperature; however, complex processes contributing to the land surface backscatter prevent the easy retrieval of PIA over land. Therefore, CloudSat liquid precipitation measurements are available over water surfaces only. Using an assumed drop size distribution, the rain rate is calculated from the difference between the observed surface backscatter and the clear-sky surface backscatter, which is determined using the PIA. A softsphere discrete dipole approximation (Liu 2004) is used to account for the scattering effects of ice particles in the cloud and a correction for multiple scattering based on a backward Monte Carlo simulation. For profiles that are fully saturated at the CloudSat wavelength, only an estimate of the minimum possible rain rate can be determined. These events are indicated by negative values in the
CloudSat data file. Since these values likely do not represent the actual rain rate (Haynes et al. 2013) and higher precipitation rates are intended to be accounted for in this study using the KuPR observations, these data have been excluded. A more detailed description of the CloudSat 2C PRECIP-COLUMN algorithm is given in Haynes et al. (2009). A separate algorithm (2C-SNOW-PROFILE; Wood et al. 2013a) was developed to retrieve snowfall rates from the CPR data. The snowfall retrieval is based on a snow rate-reflectivity algorithm where snow particle radar backscattering cross sections are calculated via the discrete dipole approximation constrained by particle models and a priori information (Wood et al. 2013a; Cooper et al. 2017). Since the snowfall retrieval algorithm does not depend on surface backscatter, the retrieval can be performed over both ocean and land surfaces. Wood et al. (2013a,b, 2014) give a more complete description of CPR snowfall retrieval, and Kulie et al. (2016) and Kulie and Milani (2018) have demonstrated the snowfall statistics using this product. For both the liquid and solid precipitation algorithms, precipitation is assumed negligible or nonexistent at reflectivities lower than $-15 \mathrm{dBZ}$ (Haynes et al. 2009). The CloudSat data used in this study were collected from January 2007 through December 2016, representing 9 years of data. These years were chosen in order to provide the largest number of samples 
available, despite the battery anomaly which caused CloudSat to lose its nighttime detection capabilities in April 2011. Errors that result from this choice of data will be discussed in section 4 . Version 5 of both CloudSat products is used here. These data can be obtained from http://www.cloudsat.cira.colostate.edu/data-products.

The average daily precipitation rates for the CPR data similar to those presented for KuPR are shown in Fig. 1b. Overall, the expected global distribution of precipitation is seen by CloudSat as well; however, the amount of precipitation measured by the CPR is much less than that measured by KuPR in many areas, especially in the ITCZ.

By comparing Figs. 1a and 1b, the strengths and weaknesses in the precipitation measurements made by both satellites can easily be seen. As stated previously, the KuPR captures well the distribution of moderate and heavy precipitation, but many regions consistently experiencing light precipitation, such as the oceanic regions off the coasts of southwestern Africa and North and South America and the band of precipitation over the midlatitude Southern Hemisphere ocean, see little to no precipitation when observed by the KuPR. When these regions are examined with the CPR, much more precipitation can be seen, due to the sensor's ability to capture these light precipitation rates. Likewise, in areas where heavy precipitation is expected, CPR measurements vastly underestimate the precipitation rate occurring, whereas the KuPR is able to record the precipitation rate more accurately. The strengths of these two satellites are highly complementary, which makes them suitable for producing a precipitation dataset that contains the full spectrum of precipitation rates.

\section{b. Methods}

The method used here for combining the CPR and KuPR precipitation rate measurements utilizes the differences in precipitation rate occurrence observed by the two satellites and is somewhat similar to the methodology presented in Behrangi et al. (2012) and Adhikari et al. (2018), but including snow precipitation and seasonal variation of precipitation rate spectra. First, the difference in resolution between the two radars is accounted for by applying a five-pixel running mean to the CPR data (Berg et al. 2010; Stephens et al. 2010; Behrangi et al. 2012). The 9 years of CPR data and the 4 years of KuPR data are then separated into $90 \mathrm{log}$-scaled precipitation rate bins ranging from 0.01 to $300 \mathrm{~mm} \mathrm{~h}^{-1}$. The bins are calculated for each $1^{\circ} \times 1^{\circ}$ grid box ranging from $65^{\circ} \mathrm{N}$ to $65^{\circ} \mathrm{S}$ for all longitudes, the observable area common to both satellites. The precipitation rates are then averaged monthly to form two separate climatologies based on each satellite (previously shown in Fig. 1). Once the datasets are so divided, the unconditional precipitation occurrence is calculated for each bin and grid box. Average occurrence per precipitation rate bin for the entire domain is shown in Fig. 2a. This shows, unsurprisingly, that the CPR records a higher occurrence of low precipitation rates than the KuPR, and conversely, KuPR shows a higher occurrence of medium to high precipitation rates. The KuPR begins recording a higher occurrence when the precipitation rate reaches approximately $2 \mathrm{~mm} \mathrm{~h}^{-1}$ on average. To form the CPR-KuPR combined dataset, occurrence plots similar to Fig. 2a are calculated for each grid box on a monthly time scale. For all precipitation rate bins where CPR observes a higher occurrence, the total amount of precipitation and number of observations of that precipitation rate obtained from the CPR are considered as the amount of precipitation and number of observations of that intensity for that month in that grid box. The same is done using KuPR data for precipitation rates where the KuPR records the higher frequency of occurrence. This produces a binned spectrum of precipitation similar to those produced by the CPR and KuPR datasets separately. This new spectrum is then averaged to produce a value of combined precipitation for each $1^{\circ} \times 1^{\circ}$ grid box. The occurrence and contribution by each precipitation rate in this combined dataset is indicated by the thick red line in Figs. 2a and 2b, respectively. This figure highlights the importance of the combined dataset, as a significant number of precipitation events from one end of the spectrum or the other are missed when considering one satellite alone.

Figure 3 shows the average number of precipitation profiles observed by GPM (KuPR; Fig. 3a), CloudSat (CPR; Fig. 3b), and the number that subsequently make up the combined dataset (Fig. 3c). The monthly average number of precipitation events comprising the combined dataset is shown per precipitation rate bin in Fig. 4, for the five points indicated in Fig. 3c. Three points were chosen along the same longitude at Northern Hemisphere, Southern Hemisphere, and equatorial latitudes, along with a CPR-dominated region off the coast of South America and a land region, where data comes only from the KuPR. These points were chosen in an attempt to display a variety of different locations and scenarios where the algorithm is applied. None of the points chosen show a deficiency in observations, except the land region (purple line), where observations of light liquid precipitation are, unsurprisingly, missing.

After producing the spectrum of combined precipitation rates similar to that depicted in Fig. 2a for each grid box, the results are averaged to a daily value and displayed in Fig. 5. It can be seen that this dataset 

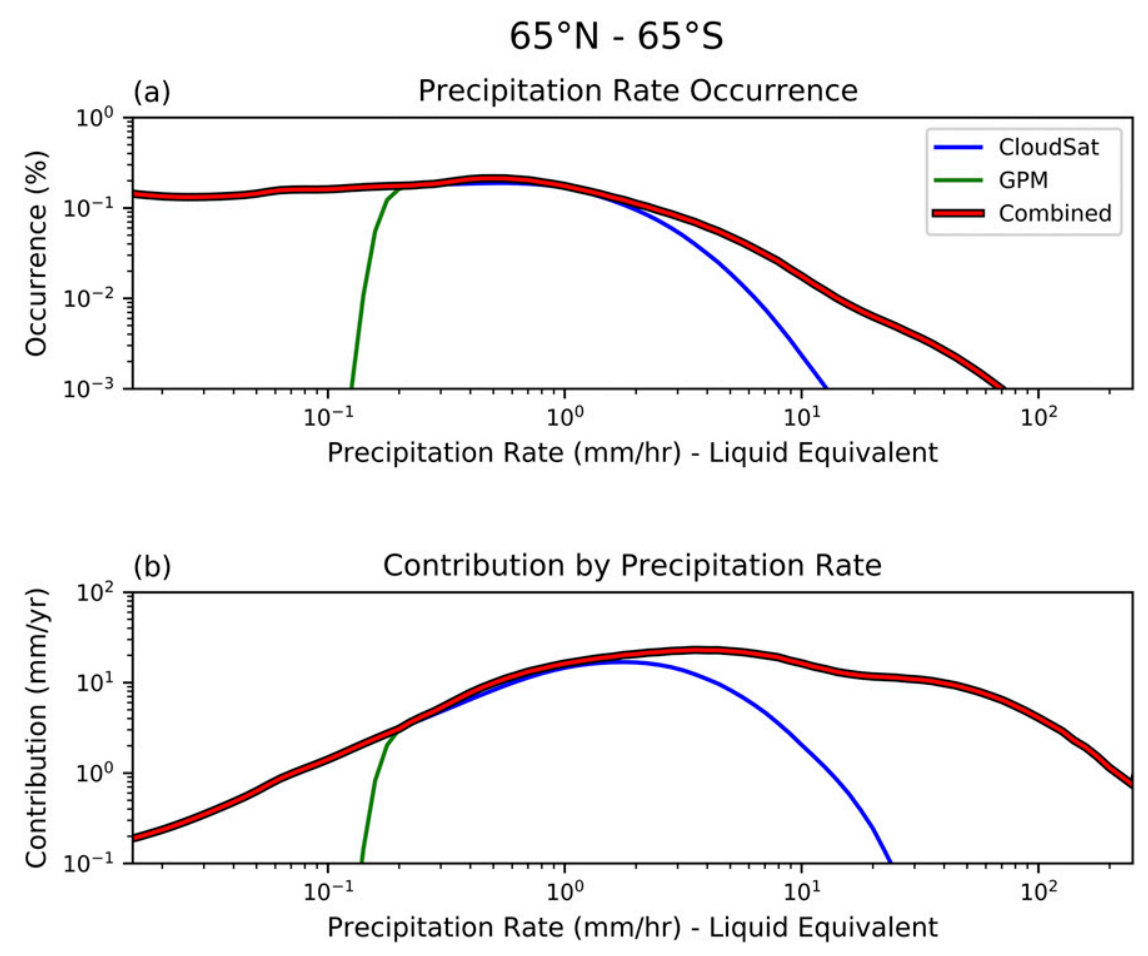

FIG. 2. (a) Unconditional occurrence and (b) contribution by precipitation rate from $65^{\circ} \mathrm{N}$ to $65^{\circ} \mathrm{S}$ for the entire CloudSat CPR, GPM KuPR, and combined datasets.

contains features observed by both the KuPR and CPR (Figs. 1a and 1b, respectively). Heavy precipitation regions such as the ITCZ and Maritime Continent are visible, as well as the relatively large amount of light precipitation occurring in stratocumulus regions, such as the midlatitude Southern Hemisphere, and near the coasts of North and South America and Africa. The relative importance of each satellite in these regions is shown in Fig. 6. In regions dominated by moderate to heavy precipitation, such as the tropics, and over land regions where CPR liquid precipitation is missing, the KuPR contributes nearly $100 \%$ of the precipitation included in the combined database (Fig. 6a). However, in midlatitude ocean regions, where light precipitation from stratocumulus clouds is more significant, the CPR contributes over $60 \%$, and in some places up to $100 \%$ of the combined database's precipitation (Fig. 6b). Berg et al. (2010) found a similar pattern of missed precipitation by the TRMM PR. Over heavy precipitation regions, such as the ITCZ, TRMM missed $10 \%$ or less of the total precipitation, but missed up to $70 \%$ of the precipitation in stratocumulus regions, especially off the western coast of South America. By accounting for precipitation from both types of features, the combined dataset presented here is a more complete precipitation dataset than that of either the GPM KuPR or CloudSat CPR alone.

\section{Results}

\section{a. Geographic distribution of precipitation}

The seasonal distributions of precipitation from the $\mathrm{KuPR}, \mathrm{CPR}$, and combined datasets are shown in Figs. 7-9, respectively. Figure 7 displays the expected seasonal features of heavy to moderate precipitation. For example, the expected northward propagation of the ITCZ in the boreal summer and subsequent southward propagation during the austral summer can be seen when comparing Fig. 7b [June-August (JJA)] and Fig. 7d [December-February (DJF)]. The stark contrast in precipitation amount over the Indian subcontinent between these two figures indicates the detection of the Indian monsoon by the GPM satellite. A double ITCZ feature is visible in Fig. 7a [March-May (MAM)], a phenomenon described first from satellite observations by Kornfield et al. (1967) and likely due to La Niña conditions (Lietzke et al. 2001). La Niña conditions occurred during 2016 (www.cpc.noaa.gov), the effects of which would be visible in the KuPR data presented here. When comparing these figures for the KuPR to their counterparts for the combined dataset (Fig. 9), it is evident that these important climatological features have been retained.

Many other features appear more prominent in the combined dataset than in KuPR data. An example is the Northern Hemisphere midlatitude storm tracks, which 


\section{Average Number of Precipitation Events Observed Monthly}

(a) GPM

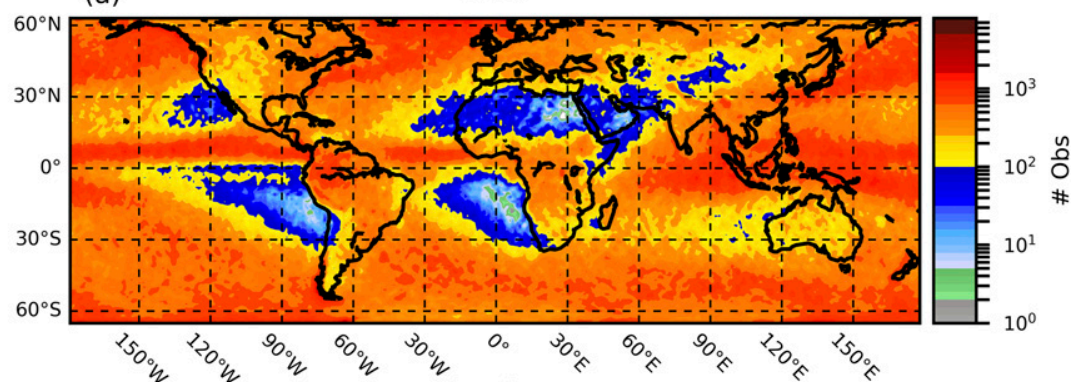

(b)

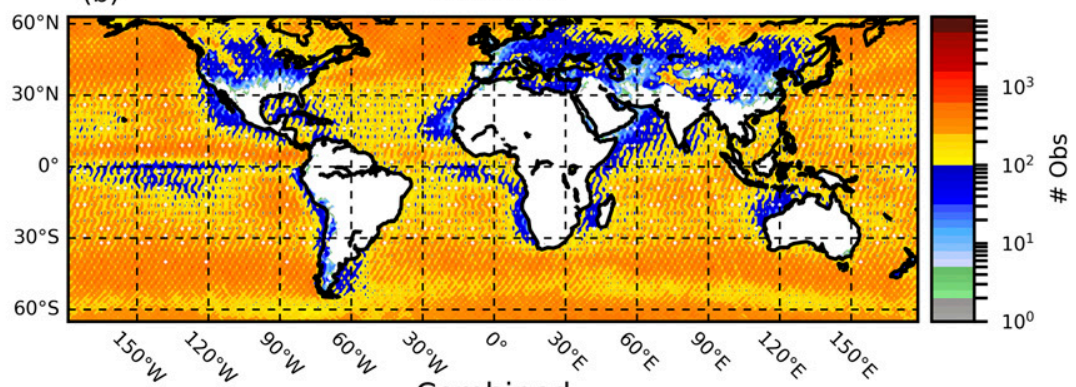

(c)

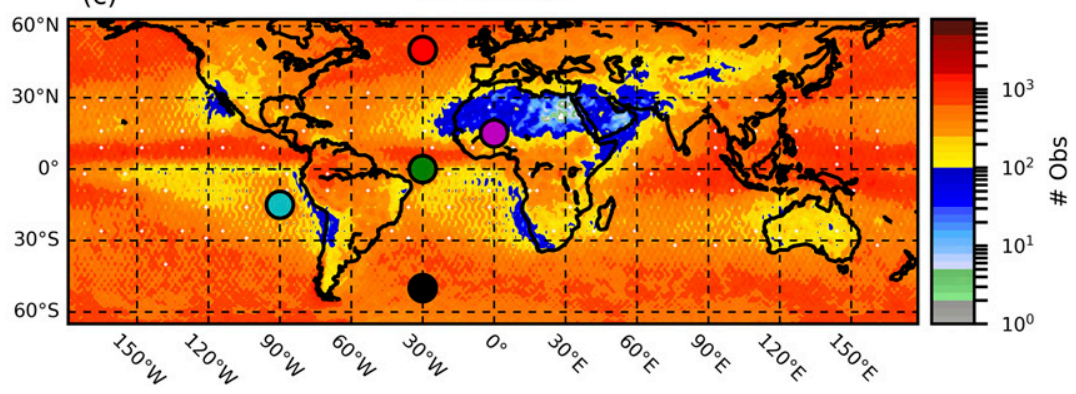

FIG. 3. Average number of precipitation events observed per month by (a) GPM KuPR and (b) CloudSat CPR. This gives (c) the average number of events per month used to form the combined dataset. The average number of observations per precipitation rate for the indicated points is given in Fig. 4.

are visible in all seasons with varying intensity. In September-November (SON), KuPR observes a large amount of precipitation in the northern Atlantic Ocean (Fig. 7c). When compared with the corresponding figure for the combined dataset (Fig. 9c), however, precipitation in this region is much more widespread. This is the result of the addition of weak precipitation in this region from CPR observations (Fig. 8c), and, if it is assumed interannual variability is small, highlights the KuPR's inability to detect weak precipitation, as well as the importance of the inclusion of these missed events in an analysis of precipitation.

There are also several important climatological features that the CPR data contribute to the combined dataset. The widespread band of light precipitation in the Southern Hemisphere ocean is one such feature, prominently visible in all four seasons (Fig. 8). Heavier precipitation is observed in this region in the austral winter (JJA; Fig. 8b) than during the austral summer (DJF; Fig. 8d). This is supported by in situ observation (Boers et al. 1996, 1998), as well as prior satellite studies of the region (Mace and Avey 2017). A region of light precipitation (1-2 $\mathrm{mm}$ day $^{-1}$ on average) can be seen off the western coast of South America in JJA, SON, and DJF (Figs. 8b-d). These features are also observed in the corresponding panels of Fig. 9, indicating that the prominent features of the distribution of light precipitation have also been preserved.

The zonally averaged distribution of precipitation from the CloudSat CPR, GPM KuPR, and the combined dataset is shown in Fig. 10. The expected distribution of precipitation is shown for each dataset, with peaks at tropical and middle latitudes and lower amounts of precipitation near approximately $20^{\circ} \mathrm{N}$ and $20^{\circ} \mathrm{S}$. The relative 


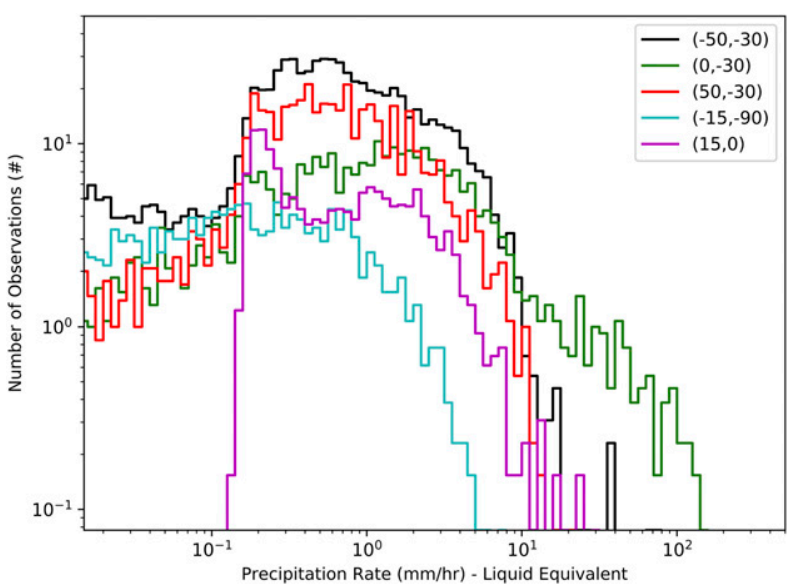

FIG. 4. Monthly average number of precipitation profiles per precipitation rate bin used to form the combined dataset for the five points indicated in Fig. 3c.

contribution of each satellite to the combined precipitation amount is also apparent. This figure highlights the previously mentioned dominance of KuPR observations at tropical latitudes and the increasing importance of the CPR at higher latitudes, especially in the Southern Hemisphere. This can also be seen in Table 1, where the mean unconditional precipitation for different latitude regions is presented for each dataset. In tropical regions $\left(20^{\circ} \mathrm{N}-20^{\circ} \mathrm{S}\right)$, the amount of precipitation over the ocean observed by the KuPR is over 3 times that observed by the CPR, and thus $\mathrm{KuPR}$ and combined precipitation amounts for this region are nearly identical. In midlatitude regions $\left(65^{\circ}-40^{\circ} \mathrm{N}\right.$ and $\left.40^{\circ}-65^{\circ} \mathrm{S}\right)$, however, ocean precipitation seen by the CPR is slightly greater than that observed by the KuPR, and the combined precipitation amount in this region is closer to the CPR observation than in other latitude bands. Differentiation between land and ocean for Table 1 was determined by applying a $1^{\circ} \times 1^{\circ}$ binary land-ocean mask. This was used instead of the land-ocean differentiation made by the satellites' retrieval algorithms for consistency across both satellites. There is a slight discrepancy between the precipitation amounts from the KuPR and combined over land, especially in the subtropical and tropical regions. While there is a small amount of precipitation over land in this region observed by the CPR, in the form of snow over the Andes, the majority of the difference in precipitation over land between KuPR and combined in these regions is due to areas identified as land by the $1^{\circ} \times 1^{\circ}$ mask but determined to be ocean by CPR's finer resolution. These values have been left off of Table 1 in order to avoid confusion, as most are not truly land precipitation, but they are still included in the dataset. The CPR-KuPR combined database contains the important and prominent global precipitation features of both CPR and KuPR observations, all of which are previously observed and well known (e.g., Adler et al. 2003, Boers et al. 1996, 1998, Kornfield et al. 1967, Mace and Avey 2017, Huffman et al. 1997).

The amount of precipitation contributed to the combined database by KuPR observations is displayed in Fig. 11. This is similar to Fig. 6a, but for each season. Regions where KuPR detection of precipitation does well, and conversely where it is deficient, are apparent. Unsurprisingly, the KuPR contributes nearly $100 \%$ of the precipitation occurring over land and in deep convective oceanic regions such as the tropics. The exception is at high latitudes and altitudes in the Northern Hemisphere when snow is possible. This is especially true during DJF (Fig. 11d) when KuPR detection is as low as $15 \%-20 \%$ over northern high-latitude land and the Tibetan Plateau, indicating a significant contribution from light snow. There is also significant underestimation by the KuPR in several oceanic regions when progressing toward the poles in both hemispheres. This is especially true in the widespread stratocumulus regions off the western coasts of Africa and North and South America. The KuPR detects less than $20 \%$ of the precipitation occurring over large areas in these regions,

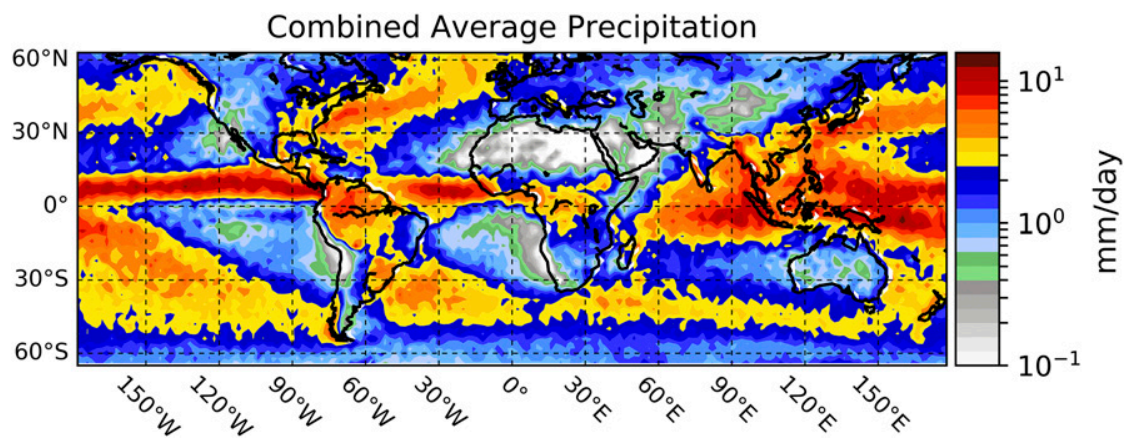

FIG. 5. Daily average precipitation from the combined dataset. 
(a)

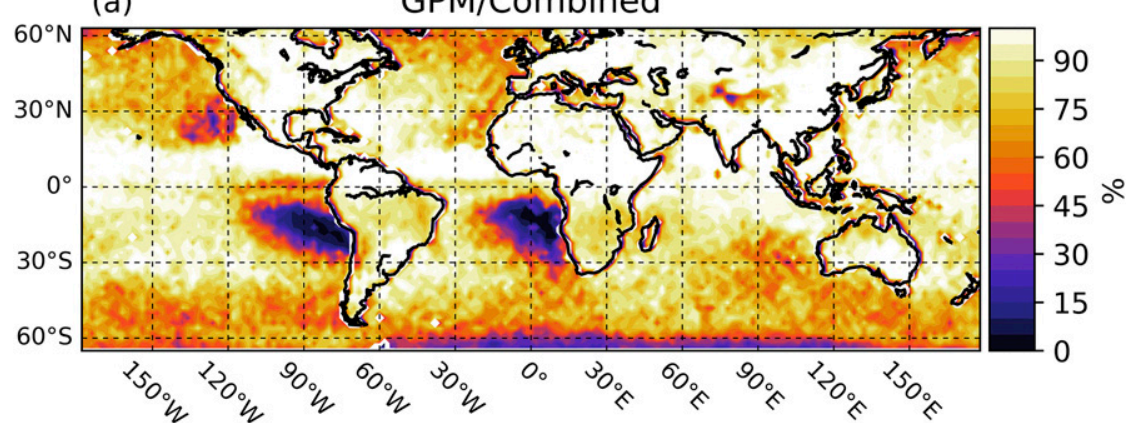

(b)

CloudSat/Combined

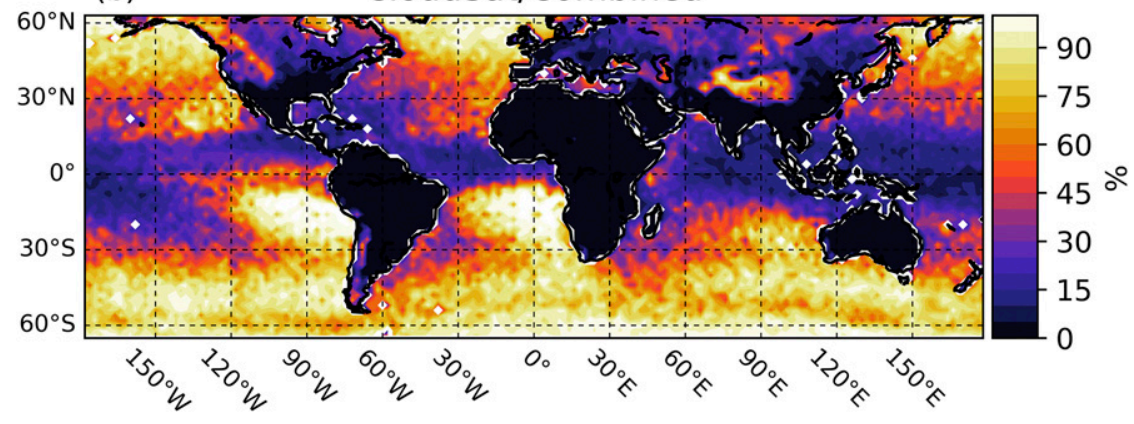

FIG. 6. Fraction of the combined dataset contributed by (a) GPM KuPR and (b) CloudSat CPR.

particularly in the two Southern Hemisphere regions during JJA and SON (Figs. 11b,c). Continuing southward, there is a widespread shallow precipitation over the Southern Ocean between approximately $30^{\circ}$ and $60^{\circ} \mathrm{S}$. KuPR detection is higher in this region, though still only about $60 \%$ on average during all seasons.

The contribution to the total precipitation by different precipitation rates is shown in Fig. 12. These percentages have been calculated using the combined precipitation amounts. Contribution by light precipitation rates $\left(<0.5 \mathrm{~mm} \mathrm{~h}^{-1}\right)$ is shown in Fig. 12a. The regions where stratocumulus clouds are dominant, off the western coasts of the continents, especially South America and Africa, and in the Southern Ocean, show the highest percentage contribution from these low precipitation rates. Low precipitation rates also contribute a relatively high percentage of the precipitation over high-latitude land, indicating the importance of snowfall in these regions. Conversely, the percent contribution from precipitation rates greater than $20 \mathrm{~mm} \mathrm{~h}^{-1}$ and greater than $50 \mathrm{~mm} \mathrm{~h}^{-1}$ are shown in Figs. 12b and 12c, respectively. The contribution from these higher precipitation rates show a similar distribution to each other, with the highest percentages being found at tropical latitudes, especially over the Maritime Continent and along the equator near the western coast of Africa. According to Liu (2011), 50\% of the rainfall in these regions comes from systems with an echo-top height greater than $10 \mathrm{~km}$. Relatively high contributions from more intense precipitation rates can also be seen in the Gulf of Mexico, the Arabian Sea, and the Bay of Bengal (Fig. 12b).

\section{b. Cloud properties}

In addition to information about the global distribution of precipitation, the combined database also contains information about the dominant cloud properties in a region, by way of the combination algorithm. Figure 13 shows the geographic and seasonal distribution of the minimum rain rate at which the occurrence observed by the KuPR becomes higher than that observed by the CPR, hereafter referred to as the switch point. Higher switch points indicate areas where the KuPR may underestimate precipitation, due to KuPR's inability to detect the precipitation predominantly occurring in these regions. This may be related to KuPR's relatively large footprint missing the small size of these precipitation events or to the smaller drop sizes associated with these light rain events, due to either aerosol or meteorological impacts, or weak snow events with smaller ice crystals.

Some regions show higher switch points than the surrounding regions (values of $1-2 \mathrm{~mm} \mathrm{~h}^{-1}$ ) during all seasons. Many of these regions were identified to be areas where the climatological occurrence of marine stratocumulus clouds is high, for example, the oceanic regions defined by Klein and Hartmann (1993) as the Californian $\left(20^{\circ}-30^{\circ} \mathrm{N}, 120^{\circ}-130^{\circ} \mathrm{W}\right)$, Peruvian $\left(10^{\circ}-20^{\circ} \mathrm{S}, 80^{\circ}-90^{\circ} \mathrm{W}\right)$, and Namibian $\left(10^{\circ}-20^{\circ} \mathrm{S}, 0^{\circ}-10^{\circ} \mathrm{E}\right)$ stratus regions. These areas are climatologically predisposed to have a high 
GPM Average Precipitation 03/2014 - 02/2018 (a) MAM
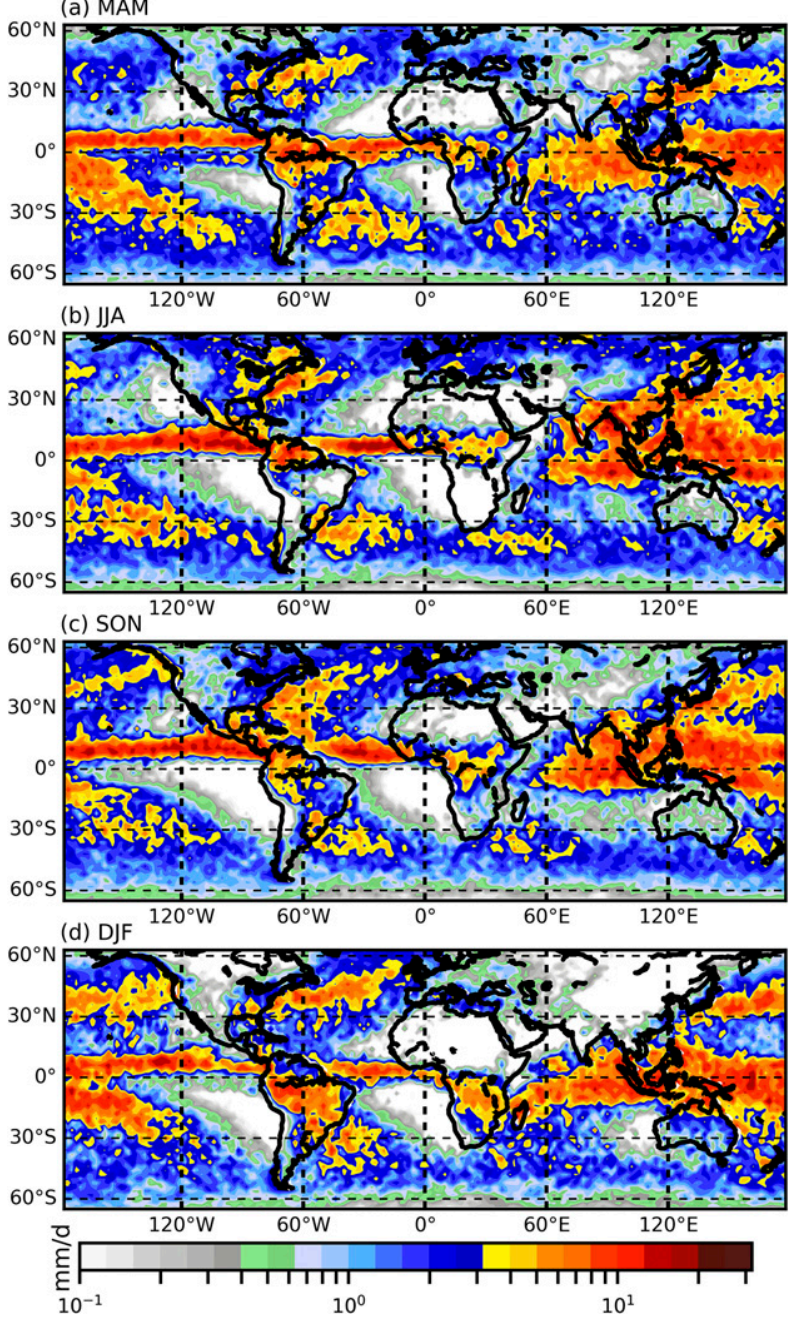

FIG. 7. Daily average precipitation $\left(\mathrm{mm} \mathrm{day}^{-1}\right)$ in each season as observed by the GPM KuPR for (a) MAM, (b) JJA, (c) SON, and (d) DJF.

occurrence of marine stratocumulus clouds and the accompanying small cloud droplet sizes and low rain rates due to the large-scale subsidence, cold sea surface temperatures, and high static stability that dominate as a result of large-scale atmospheric and oceanic circulations (Klein and Hartmann 1993; Wood 2012). Thus, the GPM $\mathrm{KuPR}$ has difficulty detecting precipitation occurring in these regions year round. Seasonal variations in switch point over areas where low-level stratocumulus clouds occur frequently are likely due to seasonal changes in cloud and precipitation amount. Klein and Hartmann (1993) analyzed variations in several large-scale dynamic and thermodynamic variables and found that low-level static stability had the highest correspondence to stratocumulus cloud amount. They found that the Namibian
CloudSat Average Precipitation 01/2007 - 12/2016 (a) MAM

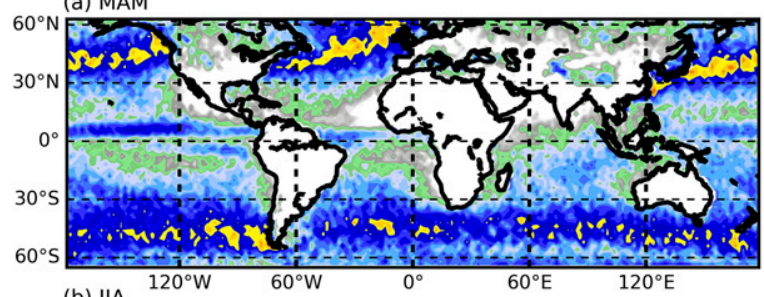

(b) JJA
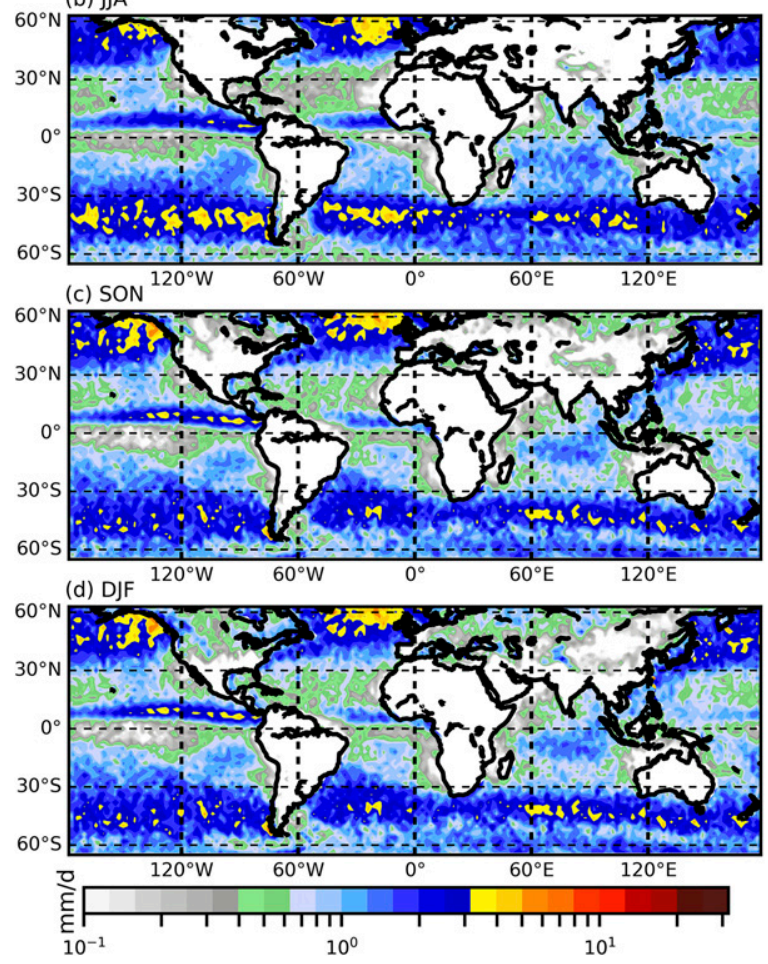

FIG. 8. As in Fig. 7, but as observed by the CloudSat CPR.

and Peruvian regions had the highest static stability and largest cloud amounts during SON. High static stability was associated with a minimum in sea surface (and consequently surface air) temperature during SON (Klein and Hartmann 1993). SON and JJA have the highest switch points in those regions, with the area of increased switch point $\left(>4 \mathrm{~mm} \mathrm{~h}^{-1}\right)$ also appearing the most widespread during these seasons (Figs. 13b,c). MAM and DJF also show areas with very high switch point, though over smaller areas, which is indicative of the year-round dominance of stratocumulus clouds in these regions. High switch point areas in the Californian stratocumulus region are less well defined than the Peruvian and Namibian regions, but appear highest during JJA and smallest during DJF. JJA is the season of peak cloud amount and static stability described by Klein and Hartmann (1993) while DJF was described as the minimum. It is important to include light precipitation in 

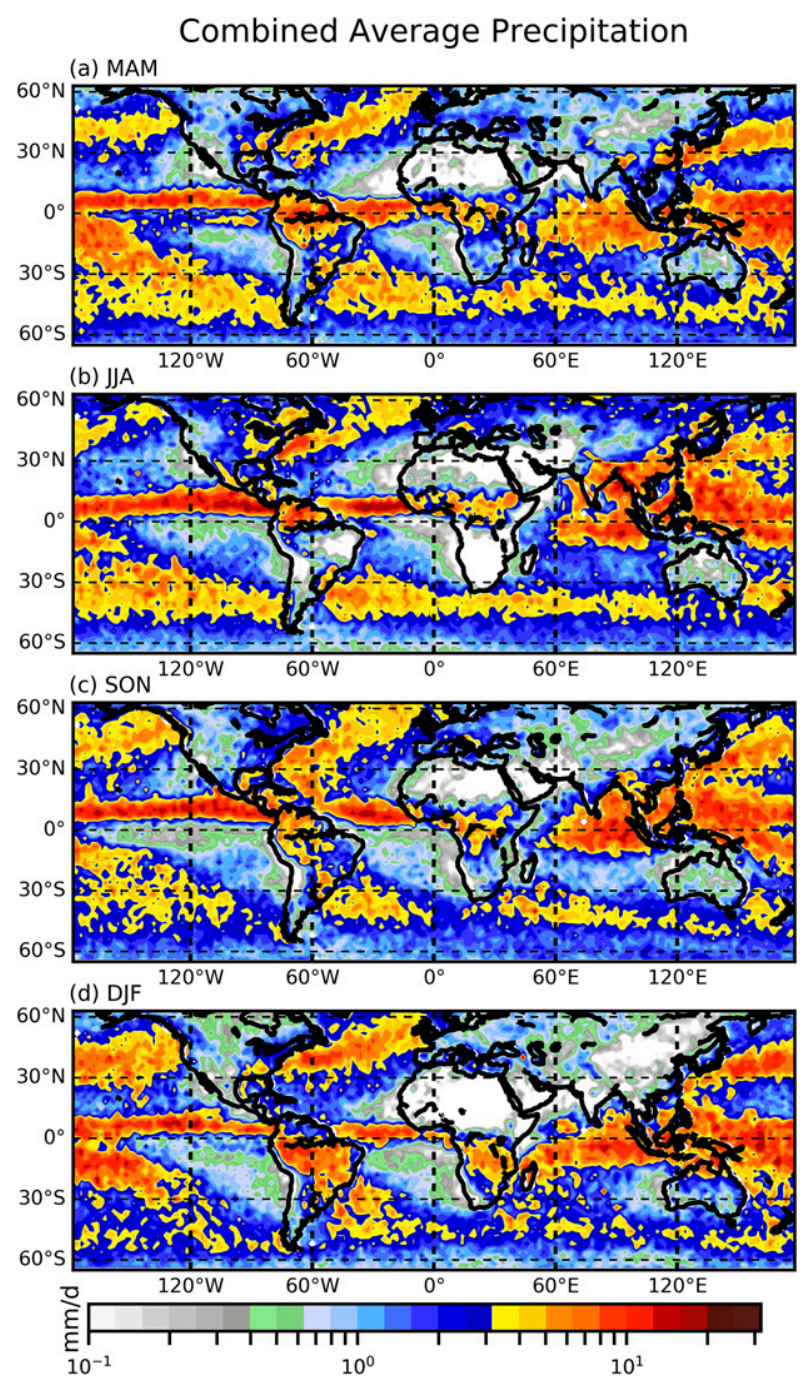

FIG. 9. As in Fig. 7, but for the CPR-KuPR combined dataset.

regions where stratocumulus clouds are common since these types of events contribute the majority of the precipitation that occurs there (Wood 2012).

Besides the regions climatologically predisposed to have a high occurrence of stratocumulus clouds, increased switch points also occur in regions where the cloud microphysical properties have been affected by the addition of aerosols. Berg et al. (2006) described observations of rainfall in the South China Sea by the TRMM satellite where the PR was unable to detect light rainfall occurring during DJF, while the TRMM Microwave Imager (TMI), a passive instrument on board the same satellite, was able to detect these clouds, and estimated the rain rate to be up to $4 \mathrm{~mm} \mathrm{~h}^{-1}$. They postulated that this reduction in PR detectability may have been due to indirect effects of sulfate aerosols, present at high concentrations in this region during that time. They proposed that the

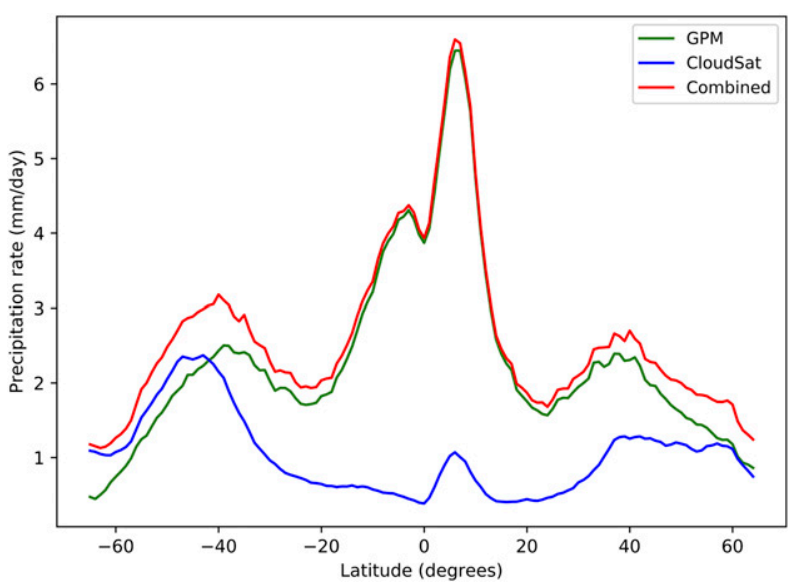

FIG. 10. Zonal average precipitation for the CloudSat CPR, GPM KuPR, and combined datasets.

increased aerosol concentration had caused a reduction in cloud droplet size via the second aerosol indirect effect (Albrecht 1989), resulting in a decrease in the reflectivity of these clouds and the missed detection by the PR. If this was indeed the cause, the KuPR data used here should experience a similar problem in high aerosol regions, as well as any other area where the average cloud droplet size is small, since the PR and the KuPR have similar wavelengths. Relatively high switch points, implying reduced detection by KuPR, are present during SON and especially DJF (Figs. 13c and $13 \mathrm{~d}$, respectively) in the South China Sea adjacent to the eastern coast of China at approximately $25^{\circ} \mathrm{N}$. This is consistent with the results of Berg et al. (2006), as they found decreased PR detection compared to TMI coincident with increased aerosol concentrations during DJF in the same region from 1997 to 2000. It is possible, then, that this increase in switch point is caused by the same phenomenon, though more supporting evidence is needed.

High aerosol concentrations are also found off the western coast of Africa, from the equator to approximately $10^{\circ} \mathrm{S}$ and extending out from the African coast past $10^{\circ} \mathrm{W}$. These high aerosol concentrations are due to biomass burning throughout central Africa from July through October and were characterized and seen to interact with the stratocumulus clouds of the region by several recent field campaigns (e.g., Zuidema et al. 2016). This appears to correspond with the increased switch points extending from the western African coast along the equator, during SON (Fig. 13c), appearing as a northward extension of the increased switch points corresponding to the Namibian stratocumulus region described earlier. This area of elevated switch point is not present during other seasons, except perhaps a slight 
TABLE 1. Mean unconditional precipitation $\left(\mathrm{mm} \mathrm{day}^{-1}\right)$ for GPM, CloudSat, and the combined dataset, over land and ocean, for the latitude ranges $20^{\circ} \mathrm{N}-20^{\circ} \mathrm{S} ; 40^{\circ}-20^{\circ} \mathrm{N}$ and $20^{\circ}-40^{\circ} \mathrm{S}$; and $65^{\circ}-40^{\circ} \mathrm{N}$ and $40^{\circ}-65^{\circ} \mathrm{S}$, as well as the latitude range for the full dataset, $65^{\circ} \mathrm{N}-65^{\circ} \mathrm{S}$.

\begin{tabular}{|c|c|c|c|c|c|}
\hline \multicolumn{2}{|c|}{$\begin{array}{c}\text { Unconditional } \\
\text { precipitation }\left(\mathrm{mm} \mathrm{day}^{-1}\right)\end{array}$} & \multirow{2}{*}{$\frac{20^{\circ} \mathrm{N}-20^{\circ} \mathrm{S}}{3.8}$} & \multirow{2}{*}{$\frac{40^{\circ}-20^{\circ} \mathrm{N} \text { and } 20^{\circ}-40^{\circ} \mathrm{S}}{2.3}$} & \multirow{2}{*}{$\frac{65^{\circ}-40^{\circ} \mathrm{N} \text { and } 40^{\circ}-65^{\circ} \mathrm{S}}{1.6}$} & \multirow{2}{*}{$\frac{65^{\circ} \mathrm{N}-65^{\circ} \mathrm{S}}{2.5}$} \\
\hline GPM & Ocean & & & & \\
\hline & Land & 3.1 & 1.3 & 1.1 & 1.7 \\
\hline & Total & 3.6 & 2.0 & 1.5 & 2.3 \\
\hline \multirow[t]{3}{*}{ CloudSat } & Ocean & 0.8 & 1.3 & 1.9 & 1.4 \\
\hline & Land & - & - & 0.4 & 0.2 \\
\hline & Total & 0.6 & 0.9 & 1.9 & 1.2 \\
\hline \multirow[t]{3}{*}{ Combined } & Ocean & 4.0 & 2.7 & 2.3 & 3.0 \\
\hline & Land & 3.0 & 1.4 & 1.3 & 1.8 \\
\hline & Total & 3.7 & 2.3 & 2.0 & 2.6 \\
\hline \multirow[t]{3}{*}{ GPCP } & Ocean & 3.5 & 3.6 & 2.9 & 2.9 \\
\hline & Land & 4.0 & 1.7 & 1.8 & 2.3 \\
\hline & Total & 3.6 & 2.3 & 2.5 & 2.8 \\
\hline
\end{tabular}

increase very near the coast during JJA (Fig. 13b). Amiri-Farahani et al. (2017) also described a link between the microphysics of marine stratocumulus and African dust in the region between $10^{\circ}$ and $40^{\circ} \mathrm{N}$ and between $10^{\circ}$ and $45^{\circ} \mathrm{W}$. Analysis of this region showed a plume of dust extending off the coast of Africa from approximately $15^{\circ}$ to $25^{\circ} \mathrm{N}$. Their study showed an increase in shallow clouds and an increased negative aerosol-cloud radiative effect in this region during JJA when the aerosol optical depth was highest and the dust plume extended farthest. Switch point increases slightly along a line extending from the west coast of Africa at approximately $15^{\circ} \mathrm{N}$ during JJA (Fig. 13b), possibly caused by this change in cloud properties and amounts.

The tropical eastern Pacific region near the equator also shows high switch point values $\left(\sim 5-6 \mathrm{~mm} \mathrm{~h}^{-1}\right)$, especially during JJA and SON (Figs. 13b,c). Few in situ studies have been conducted in this region; however, it was observed to be a region of low TRMM PR rainfall detectability by Shige et al. (2008). This underestimation in PR rainfall over this area was attributed to smaller drop sizes and greater frequency of low cloud tops when compared to the tropical western Pacific. Munchak et al. (2012) also found smaller droplet sizes in this region and postulated that this may be the result of lower updraft speeds in clouds forming here since they are far from land and thus have relatively small CAPE. They also observed that this region had a higher frequency of clouds that existed entirely below freezing, eliminating the possibility of increases in droplet size from coldcloud processes. High switch points and increased KuPR underestimation are thus expected in this area.

In the Southern Hemispheric ocean poleward of $30^{\circ} \mathrm{S}$, underestimation may occur at rain rates up to $2 \mathrm{~mm} \mathrm{~h}^{-1}$. Observations have shown that aerosol amount and cloud droplet number concentrations are higher during
DJF than JJA (Yum and Hudson 2004; Boers et al. 1998), but the switch point shows an opposite trend. Thus, the changing switch point in this region is likely due to CloudSat observing a higher occurrence of precipitation for all precipitation rates in JJA, while KuPR observes little difference in precipitation occurrence between winter and summer, especially for precipitation rates lower than $3 \mathrm{~mm} \mathrm{~h}^{-1}$ (not shown). We speculate that both small liquid- and ice-form hydrometeors during these seasons would lead to much lower reflectivity. These small particles are more difficult for the KuPR to detect, given the same precipitation rate. An additional interesting feature visible in this region is the presence of a narrow band of low switch points within the more widespread area of high switch point values in this region. This may be the result of increased droplet sizes and thus reflectivities caused by the melting of ice-form hydrometeors, similar to a brightband effect. Also plotted in Fig. 13 is the seasonal average $2-\mathrm{m} 0^{\circ} \mathrm{C}$ isotherm determined from the European Centre for Medium-Range Weather Forecasts (ECMWF) ERAInterim reanalysis data (Dee et al. 2011). This can be seen to follow the southern edge of this low switch point band quite closely, implying that the transition back to high switch points is due to precipitation reaching the ground as snow rather than rain, subsequently resulting in lower reflectivites. This brightband region is also visible at midlatitudes in the Northern Hemisphere and is most easily visible during DJF (Fig. 13d) off the northwestern coast of North America and the northeastern coast of Asia. Switch points in these midlatitude regions are still relatively high overall compared to other areas, which is indicative of the comparatively small hydrometeor size and shallow cloud depth, making these regions and the midlatitude Southern Hemisphere in particular an area of significant KuPR underestimation. 

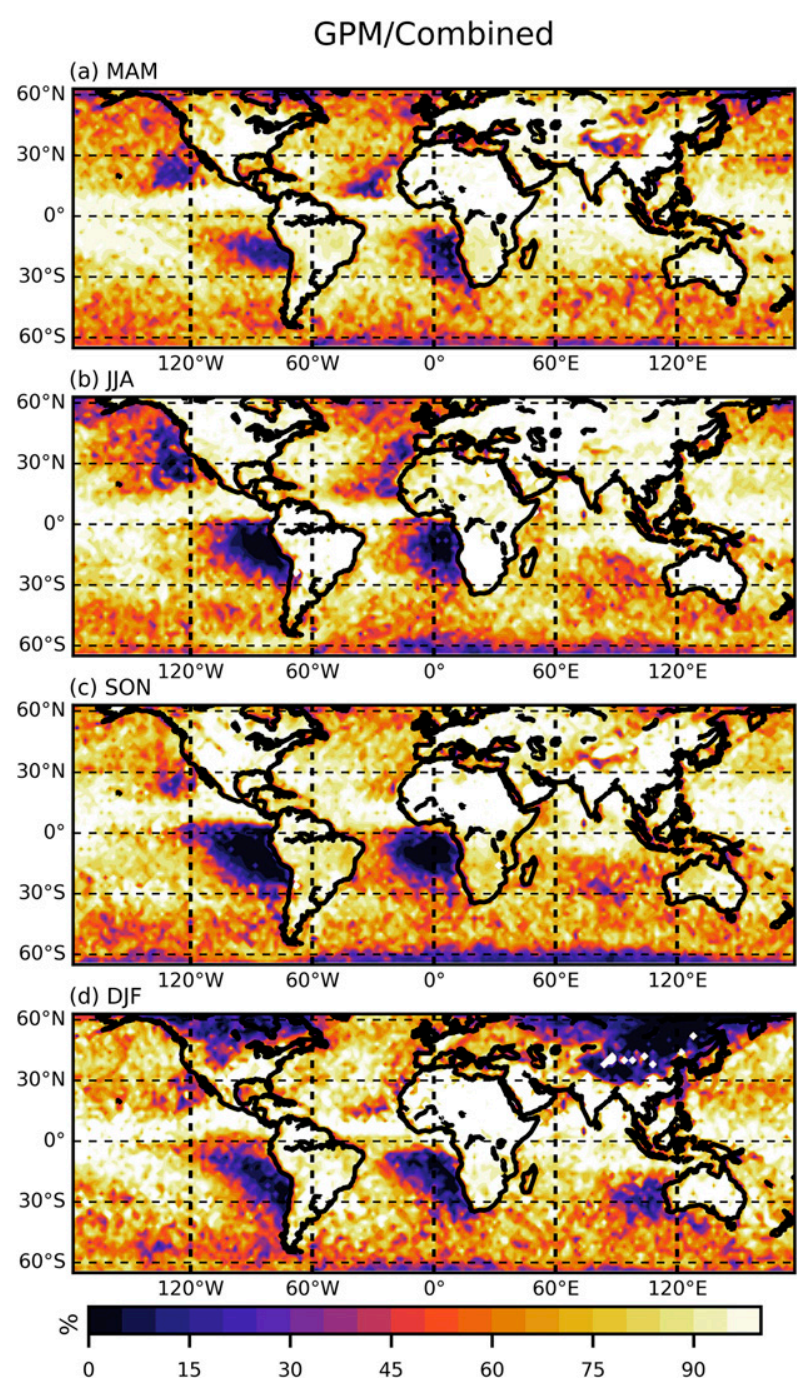

FIG. 11. Fraction of the combined dataset contributed by GPM KuPR for (a) MAM, (b) JJA, (c) SON, and (d) DJF.

\section{Discussion}

\section{a. Comparison with GPCP}

To validate the climatology presented here, a brief comparison with data from the GPCP was performed. The GPCP (Huffman et al. 1997, 2009; Adler et al. 2003, 2016) is a climatology produced from a combination of passive satellite precipitation measurements and Global Precipitation Climatology Centre (GPCC) precipitation gauge measurements. The satellite precipitation estimates utilized by the GPCP include passive microwave estimates from the Special Sensor Microwave Imager (SSM/I) instruments, IR-based estimates from the Geostationary Operational Environmental Satellite (GOES) Precipitation Index (GPI) and Advanced Very High Resolution Radiometer (AVHRR) data, and estimates from the Television and Infrared Observation Satellite (TIROS) Operational Vertical Sounder (TOVS) and Outgoing Longwave Radiation (OLR) measurements, which are used for SSM/I gap filling and during the preSSM/I period, respectively (Adler et al. 2003). The dataset is available from 1979 to the present on a monthly time scale at $2.5^{\circ} \times 2.5^{\circ}$ spatial resolution. The latest GPCP version 2.3 (Adler et al. 2016) data were used here and were obtained from https://www.esrl.noaa.gov/psd/data/gridded/ data.gpcp.html. The comparison is presented in Fig. 14. Figure 14a shows the GPCP average daily precipitation from 2007 to 2017, which was chosen in an attempt to match the data included when producing the combined climatology. Figure 14b shows the previously presented combined dataset (see Fig. 5). Both datasets have been averaged to a common $5^{\circ} \times 5^{\circ}$ resolution in this figure for ease of comparison. A cursory comparison of the top two panels shows that the distribution of precipitation for these two datasets is highly similar. When the combined average precipitation is subtracted from the GPCP average precipitation (Fig. 14c), it can be seen that the differences in precipitation between these two datasets are typically less than $4 \mathrm{~mm}$ day $^{-1}$.

Over land, GPCP records higher average unconditional precipitation rates. This is expected, since the majority of precipitation over land in the combined dataset comes from the KuPR only, resulting in an underestimation of light precipitation in these regions. GPCP estimates of precipitation over land are not subject to this bias, since gauge data are included. Therefore, the combined dataset is less reliable than the GPCP over land regions, especially those with a high density of gauge observations. Over ocean regions, the combined dataset records more precipitation, for similar reasons; gauge data are not available to compensate for biases produced by the satellites used by GPCP, while CPR rainfall is available over oceans and can compensate for the underestimation of light rain by the KuPR. This is evidenced by the region of higher precipitation amounts shown in the combined data at midlatitudes in the Southern Hemisphere where, as was previously mentioned, the CPR is able to detect a significant amount of light rain.

A more quantitative comparison between the combined dataset and the GPCP is given in Fig. 15, with values shown in Table 1 . The mean amount of precipitation over the ocean from GPCP is similar to the combined dataset, though slightly smaller in most regions, as was previously mentioned. This is especially true over tropical $\left(20^{\circ} \mathrm{N}-20^{\circ} \mathrm{S}\right)$ and subtropical $\left(40^{\circ}-20^{\circ} \mathrm{N}, 20^{\circ}-40^{\circ} \mathrm{S}\right)$ regions (Table 1$)$. The zonal distribution (Fig. 15) over ocean is similar in shape and magnitude for both datasets, with a few differences. The tropical peak in precipitation from the combined 

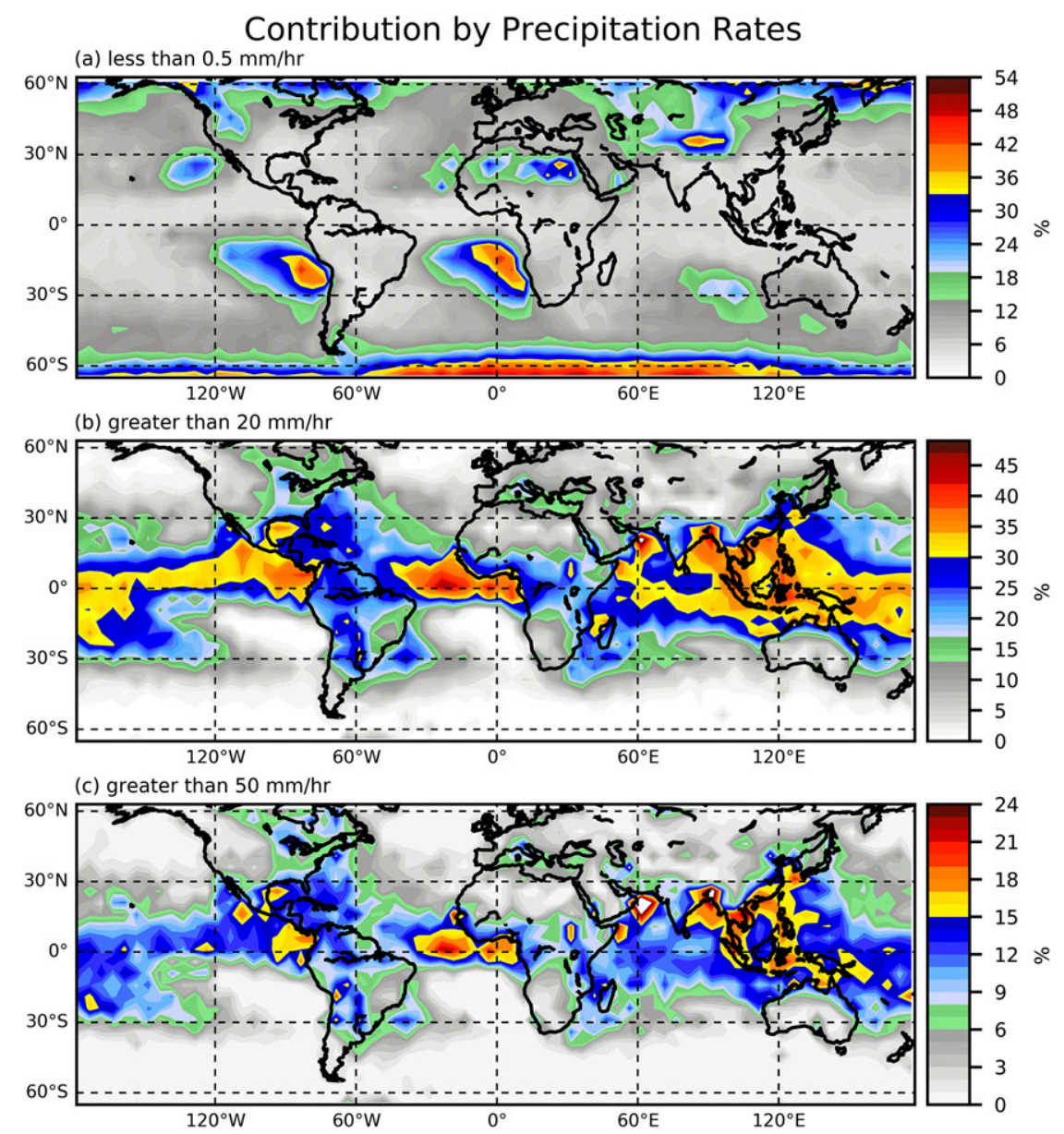

FIG. 12. Percent contribution to the total precipitation amount by precipitation rates (a) less than $0.5 \mathrm{~mm} \mathrm{~h}^{-1}$, (b) greater than $20 \mathrm{~mm} \mathrm{~h}^{-1}$, and (c) greater than $50 \mathrm{~mm} \mathrm{~h}^{-1}$, as calculated from the combined dataset.

dataset is slightly offset from that of GPCP, for both oceanic and total precipitation. The increased precipitation over the Southern Ocean (approximately $30^{\circ}-50^{\circ} \mathrm{S}$ ) by the combined dataset is again shown here. Over land, the magnitude of the underestimation of precipitation by the combined dataset can be seen at all latitudes. This underlines the need for caution when applying this dataset to land regions. Overall, when considering ocean and land regions together, precipitation from the combined dataset is similar to that from the GPCP in both distribution and magnitude.

\section{b. Sources of error}

There are several sources of error that require consideration when using the combined dataset presented here. One is that no consideration has been given to errors inherent the CPR-KuPR retrieval of precipitation. While both CPR and KuPR retrievals have documented errors (Ellis et al. 2009; Smalley et al. 2014;
Kubota et al. 2014), these errors are not taken into account when preparing this dataset. Also, since CloudSat is in a sun-synchronous orbit, the data from this satellite only contain precipitation that occurs at the same two times every day, corresponding to CloudSat's equator crossing time of approximately 0130 and 1330 local standard time. This is not expected to cause much of a discrepancy over ocean (Berg et al. 2010), as the diurnal cycle of precipitation over the oceans is not large. Berg et al. (2010) analyzed the difference in precipitation frequency and volume between the full TRMM PR dataset and data from only the CloudSat observation times and found the difference to be less than $1 \%$ for precipitation rates less than $2 \mathrm{~mm} \mathrm{~h}^{-1}$. Leon et al. (2008) estimated the diurnal cycle of precipitation in stratocumulus clouds using CloudSat. They found the day-night difference in precipitation rate in these regions was largest for the lowest quartile of precipitation rates, with these rates experiencing a slight increase in strength at 

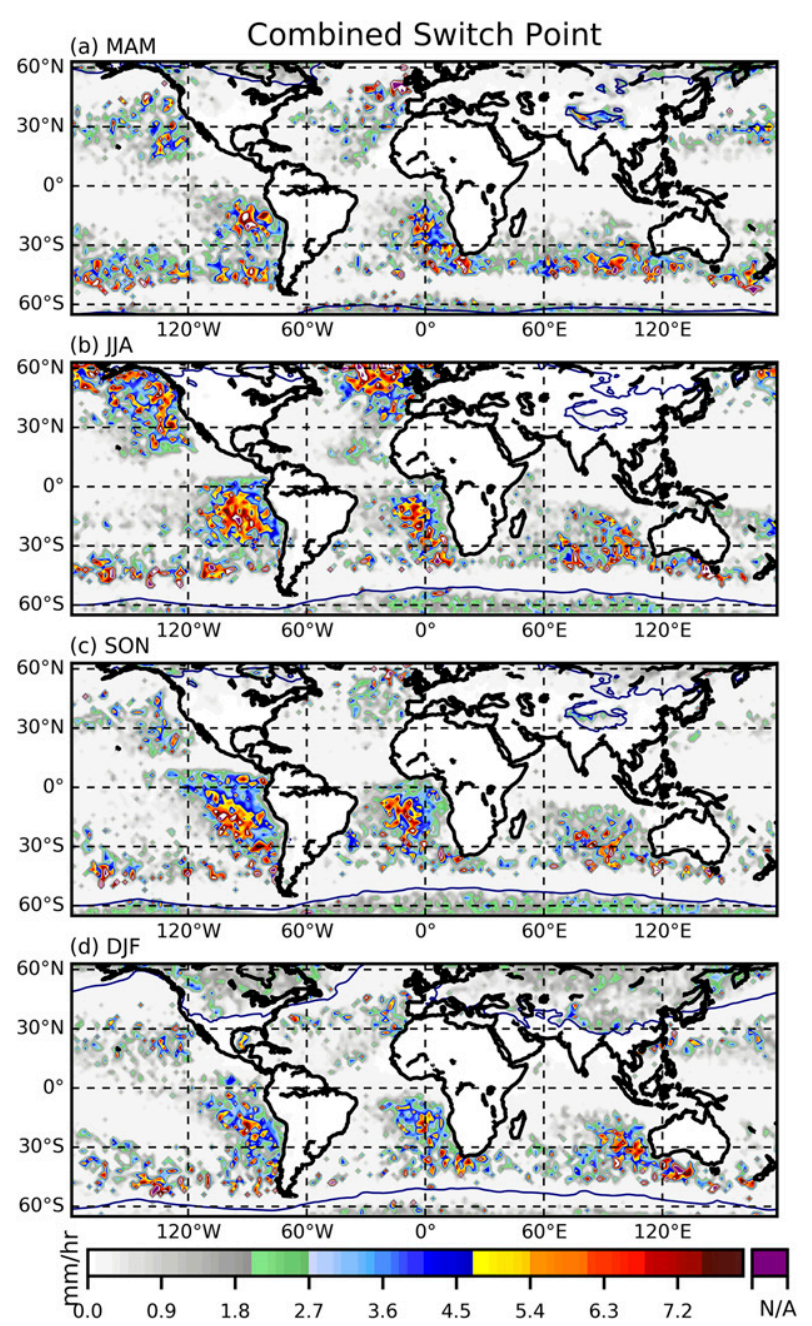

FIG. 13. Seasonal average switch point $\left(\mathrm{mm} \mathrm{h}^{-1}\right)$, the point at which the combined dataset switches from CPR to KuPR for (a) MAM, (b) JJA, (c) SON, and (d) DJF. Also indicated is the average $2-\mathrm{m} 0^{\circ} \mathrm{C}$ isotherm, determined from ECMWF reanalysis.

night. Each stratocumulus region, including both subtropical and midlatitude regions, experienced an increase of only $0.03 \mathrm{~mm}_{\text {day }}{ }^{-1}$ or less in this quartile, however. Higher precipitation rates experienced a more minimal effect. The CloudSat CPR data used here have a bias toward daytime precipitation, as nighttime observations are not available from April 2011 onward. This bias is expected to be small, due to the small diurnal cycle over ocean, especially in CPR-dominated regions. To verify this, CPR observations from 2007 to 2010 were used, comparing the full set of observations to a subset using the daytime observations only. Differences in average precipitation rate were typically small, especially when only those rates that would be included in the CPR-KuPR combined dataset were considered. For these small precipitation rates, the difference was $<1 \%$ for all ocean regions, with the highest difference $\left(0.02 \mathrm{~mm} \mathrm{day}^{-1}\right)$ being found at mid- to high latitudes.

Another source of error in this dataset that has already been mentioned is the lack of a retrieval algorithm for liquid precipitation over land using the CPR. This results in an underestimation of light liquid precipitation over land, mentioned in the previous section (see Table 1). This has the potential to introduce large errors into the dataset, which is partially demonstrated by Fig. 15; however, a quantification of this error is not attempted at this time. Future versions of this dataset will attempt inclusion of ground-based rain gauge data to account for this. As was also previously mentioned, CPR and KuPR footprint sizes are different. To account for this, a five-pixel running mean was applied to the CPR data, as was described in section $2 \mathrm{~b}$. This was chosen based on the error analysis and results of several other studies including Berg et al. (2010), Stephens et al. (2010), and Adhikari et al. (2018). The CPR was found to have a very low sensitivity to the number of pixels used to form the running mean; $\sim 1 \mathrm{~mm} \mathrm{yr}^{-1}$ or $1 \%$ (Adhikari et al. 2018). The sensitivity of the combination algorithm to the resolution has also been examined. The algorithm was rerun using KuPR and CPR data first processed into $2^{\circ} \times 2^{\circ}$ bins, rather than $1^{\circ} \times 1^{\circ}$. Differences in the resulting combined daily average precipitation were found to be $0.06 \mathrm{~mm} \mathrm{day}^{-1}$ or about $2 \%$ on average. The switch point was similarly examined and the pattern of high and low switch point values globally was found to be highly similar. The exact value of the switch point is relatively unimportant to the analysis and was typically shifted by only a few precipitation rate bins. Here the CPR and KuPR precipitation data in two different periods are combined. The interannual variation of the precipitation is assumed relatively small and neglected. However, this could still lead to an uncertainty up to $10 \%$ (Adhikari et al. 2018), and a longer record of data could help resolve this. The above sources of error should be kept in mind when using this CPR-KuPR combined precipitation dataset.

\section{Summary and conclusions}

A method for combining CloudSat CPR and GPM KuPR precipitation data has been presented here. By combining these two datasets, we have produced a more complete climatology than that produced by either satellite. The KuPR on board the GPM satellite is able to observe events with moderate to heavy precipitation rates, and the combined dataset retains the precipitation features provided by this instrument, including the ITCZ and Indian monsoon. CloudSat's CPR is able to 
(a)

GPCP 2007-2017

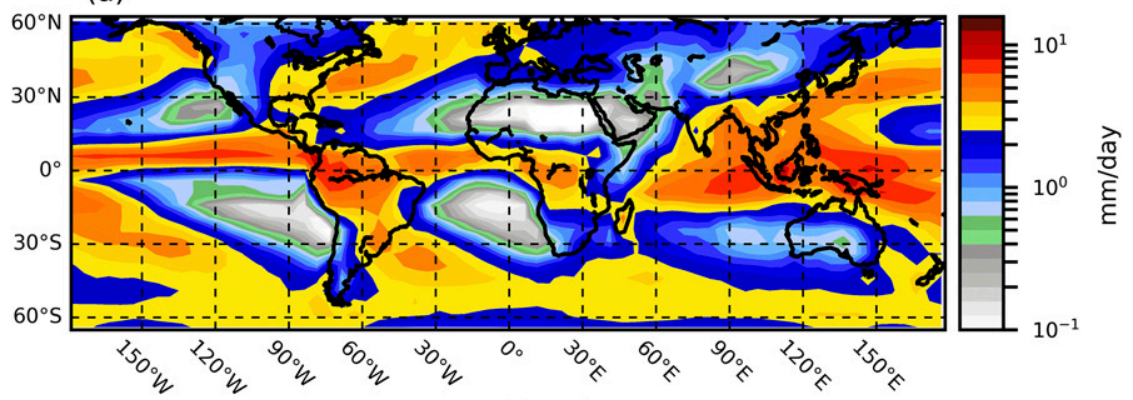

(b)

Combined

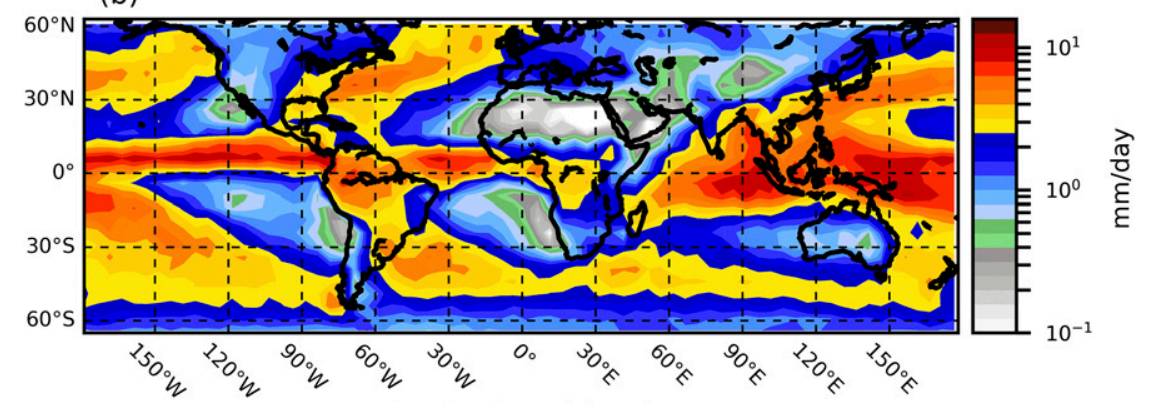

(c)

GPCP-Combined

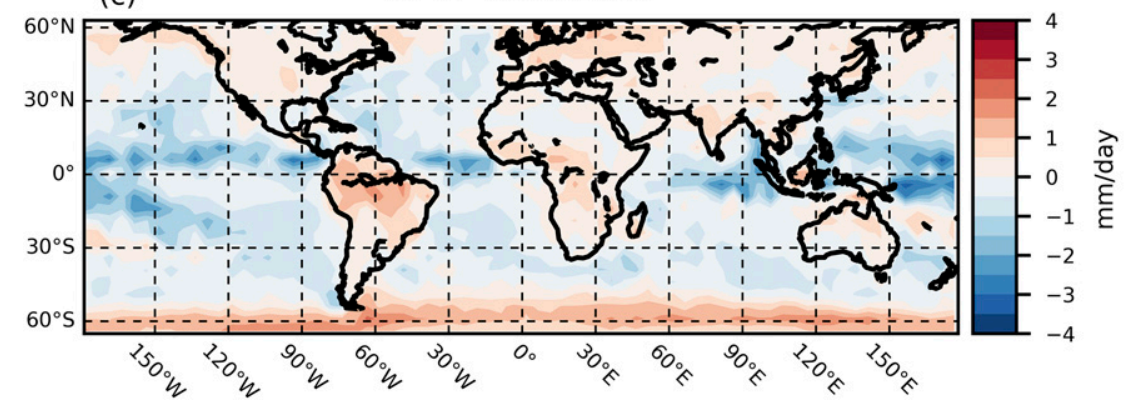

FIG. 14. Daily average precipitation from (a) GPCP (2007-17) and (b) the CPR-KuPR combined dataset. The difference is shown in (c).

observe light precipitation rate features, many of which are missed by the KuPR due to their small droplet size. These features are represented in the combined database as well and consist of many stratocumulus-dominated regions, such as the midlatitude Southern Hemisphere ocean. Precipitation from these regions, while light, is nontrivial and important to include in a precipitation climatology, since these light precipitation rates are the greatest contributors to precipitation in these regions.

The point at which the combined dataset switches from the CPR to the KuPR was also introduced as an indicator of the general microphysical properties and cloud type of the region, as well as the potential for underestimation by the KuPR in that region. In some regions, the switch point can often be greater than $2 \mathrm{~mm} \mathrm{~h}^{-1}$, and in some cases greater than $5 \mathrm{~mm} \mathrm{~h}^{-1}$, indicating that the KuPR would underestimate the amount and occurrence of precipitation from events with precipitation rates less than this. Since the regions where this occurs most often are dominated by these light precipitation events, there is the potential for significant underestimation of the precipitation in these regions. The switch point may also indicate the general microphysical properties of the region, although this requires further refinement and investigation. The combined dataset has the potential to indicate more than the climatological precipitation rate, however.

Precipitation rates from the combined dataset were compared against those from the GPCP for verification. The combined dataset is generally very comparable to the GPCP, with higher precipitation rates shown by GPCP over land and lower precipitation rates over the ocean, in general. This is likely due to the inclusion of gauge data in the GPCP accounting for the light 


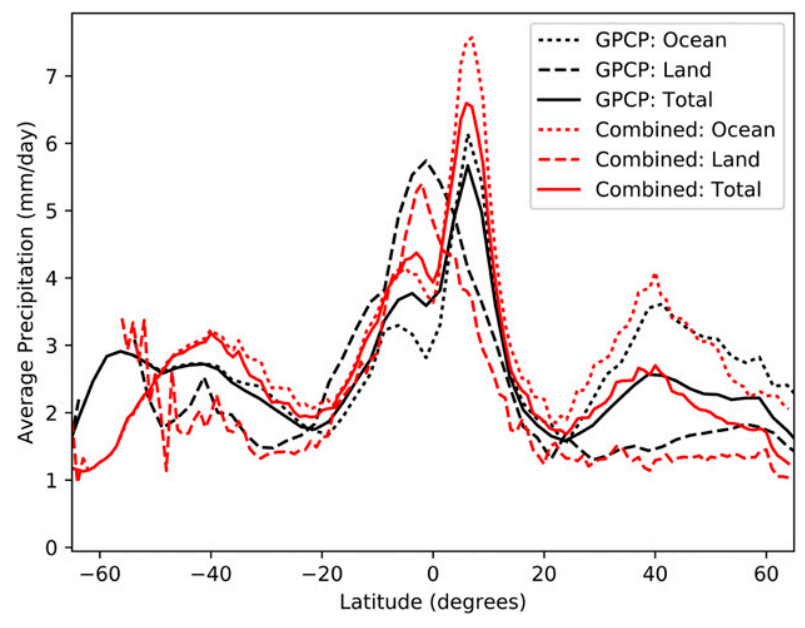

FIG. 15. Zonal average precipitation $\left(\mathrm{mm} \mathrm{day}^{-1}\right)$ including ocean only, land only, and total for the CPR-KuPR combined dataset and GPCP (2007-17).

precipitation over land and the inclusion of CPR data in the combined database accounting for light precipitation over the ocean. A useful next step for the combined database would be the inclusion of gauge data, to fill in the missing weak precipitation over land.

Several sources of error are inherent in the combined database, which warrant consideration when using the data presented here. These errors include the lack of light precipitation over land, the diurnal sampling bias from CloudSat's non-sun-synchronous orbit and lack of nighttime observations for much of the time period, different footprint sizes of the two radars, and retrieval errors. Where possible, an attempt at quantification of these errors has been made, often resulting in a difference of less than $1 \%$, with the largest quantified source of error being the interannual variability $(\sim 10 \%)$. Overall, many of the abovementioned errors are small, and the combined dataset should give a reasonable estimate of precipitation, at least over ocean regions. As the methodology can be expanded to include other datasets, some of these errors may be reduced, especially through the inclusion of gauge data to account for light precipitation over land. By combining measurements of precipitation from multiple sensors, the strengths of each can be exploited and a more complete spectrum of precipitation can be represented.

Acknowledgments. This research was supported by NASA Precipitation Measurement Mission Grants NNX16AD76G under the direction of Dr. Ramesh Kakar and NNX16AH74G under the direction of Dr. Erich Stocker. Thanks to the Precipitation Processing System (PPS) team at NASA Goddard Space Flight Center, Greenbelt, MD, for data processing assistance.

\section{REFERENCES}

Adhikari, A., C. Liu, and M. Kulie, 2018: Global distribution of snow precipitation features and their properties from three years of GPM observations. J. Climate, 31, 3731-3754, https:// doi.org/10.1175/JCLI-D-17-0012.1.

Adler, R. F., and Coauthors, 2003: The version-2 Global Precipitation Climatology Project (GPCP) monthly precipitation analysis (1979-present). J. Hydrometeor., 4, 1147-1167, https://doi.org/ 10.1175/1525-7541(2003)004<1147:TVGPCP $>2.0$.CO;2.

— , and Coauthors, 2016: The new version 2.3 of the Global Precipitation Climatology Project (GPCP) monthly analysis project. University of Maryland Rep., 8 pp., http://eagle1.umd. edu/GPCP_ICDR/GPCP_Monthly.html.

Albrecht, B., 1989: Aerosols, cloud microphysics, and fractional cloudiness. Science, 245, 1227-1230, https://doi.org/10.1126/ science.245.4923.1227.

Amiri-Farahani, A., R. J. Allen, D. Neubauer, and U. Lohmann, 2017: Impact of Saharan dust on North Atlantic marine stratocumulus clouds: Importance of the semidirect effect. Atmos. Chem. Phys., 17, 6305-6322, https://doi.org/10.5194/ acp-17-6305-2017.

Behrangi, A., M. Lebsock, S. Wong, and B. Lambrigtsen, 2012: On the quantification of oceanic rainfall using spaceborne sensors. J. Geophys. Res., 117, D20105, https://doi.org/ 10.1029/2012JD017979.

Berg, W., T. L'Ecuyer, and C. Kummerow, 2006: Rainfall climate regimes: The relationship of regional TRMM rainfall biases to the environment. J. Appl. Meteor. Climatol., 45, 434-454, https://doi.org/10.1175/JAM2331.1.

$\longrightarrow, \ldots$, and J. M. Haynes, 2010: The distribution of rainfall over oceans from spaceborne radars. J. Appl. Meteor. Climatol., 49, 535-543, https://doi.org/10.1175/2009JAMC2330.1.

Boers, R., J. B. Jensen, P. B. Krummel, and H. Gerber, 1996: Microphysical and short-wave radiative structure of wintertime stratocumulus clouds over the Southern Ocean. Quart. J. Roy. Meteor. Soc., 122, 1307-1339, https://doi.org/ 10.1002/qj.49712253405.

,-- , and - , 1998: Microphysical and short-wave radiative structure of stratocumulus clouds over the Southern Ocean: Summer results and seasonal differences. Quart. J. Roy. Meteor. Soc., 124, 151-168, https://doi.org/10.1002/ qj. 49712454507.

Cooper, S. J., N. B. Wood, and T. S. L'Ecuyer, 2017: A variational technique to estimate snowfall rate from coincident radar, snowflake, and fall-speed observations. Atmos. Meas. Tech., 10, 2557-2571, https://doi.org/10.5194/amt-102557-2017.

Dee, D. P., and Coauthors, 2011: The ERA-Interim reanalysis: Configuration and performance of the data assimilation system. Quart. J. Roy. Meteor. Soc., 137, 553-597, https:// doi.org/10.1002/qj.828.

Ellis, T. D., T. L'Ecuyer, J. M. Haynes, and G. L. Stephens, 2009: How often does it rain over the global oceans? The perspective from CloudSat. Geophys. Res. Lett., 36, L03815, https:// doi.org/10.1029/2008GL036728.

Hamada, A., and Y. N. Takayabu, 2016: Improvements in detection of light precipitation with the Global Precipitation Measurement Dual-Frequency Precipitation Radar (GPM DPR). J. Atmos. Oceanic Technol., 33, 653-667, https://doi.org/10.1175/ JTECH-D-15-0097.1.

Haynes, J. M., T. S. L'Ecuyer, G. L. Stephens, S. D. Miller, C. Mitrescu, N. B. Wood, and S. Tanelli, 2009: Rainfall 
retrieval over the ocean with spaceborne W-band radar. J. Geophys. Res., 114, 2156-2202, https://doi.org/10.1029/ 2008JD009973.

,,-- D. Vane, G. Stephens, and D. Reinke, 2013: Level 2-C Precipitation Column Algorithm Product process description and interface control document. JPL Doc., 17 pp., http:// www.cloudsat.cira.colostate.edu/sites/default/files/products/ files/2C-PRECIP-COLUMN_PDICD.P2_R04.20130124.pdf.

Hitschfeld, W., and J. Bordan, 1954: Errors inherent in the radar measurement of rainfall at attenuating wavelengths. J. Meteor., 11, 58-67, https://doi.org/10.1175/1520-0469(1954) $011<0058$ :EIITRM $>2.0$. CO;2.

Hou, A., and Coauthors, 2014: The Global Precipitation Measurement Mission. Bull. Amer. Meteor. Soc., 95, 701-722, https://doi.org/10.1175/BAMS-D-13-00164.1.

Huffman, G. J., and Coauthors, 1997: The Global Precipitation Climatology Project (GPCP) combined precipitation dataset. Bull. Amer. Meteor. Soc., 78, 5-20, https://doi.org/10.1175/ 1520-0477(1997)078<0005:TGPCPG >2.0.CO;2.

—_, and Coauthors, 2007: The TRMM multisatellite precipitation analysis (TMPA): Quasi-global, multiyear, combined-sensor precipitation estimates at fine scales. J. Hydrometeor., 8, 38-55, https://doi.org/10.1175/JHM560.1.

——, R. F. Adler, D. T. Bolvin, and G. Gu, 2009: Improving the global precipitation record: GPCP Version 2.1. Geophys. Res. Lett., 36, LI7808, https://doi.org/10.1029/ 2009GL040000.

Iguchi, T., S. Seto, R. Meneghini, N. Yoshida, J. Awaka, M. Le, V. Chandrasekar, and T. Kubota, 2017: GPM/DPR level-2. Algorithm Theoretical Basis Doc., 81 pp., http:// www.eorc.jaxa.jp/GPM/doc/algorithm/ATBD_DPR_201708_ whole_1.pdf.

Klein, S. A., and D. L. Hartmann, 1993: The seasonal cycle of low stratiform clouds. J. Climate, 6, 1587-1606, https://doi.org/ 10.1175/1520-0442(1993)006<1587:TSCOLS $>2.0$. CO;2.

Kornfield, J., A. F. Hasler, K. J. Hanson, and V. E. Suomi, 1967: Photograhic cloud climatology from ESSA III and V computer produced mosaics. Bull. Amer. Meteor. Soc., 48, 878-883, https://doi.org/10.1175/1520-0477-48.12.878.

Kubota, T., and Coauthors, 2014: Evaluation of precipitation estimates by at-launch codes of GPM/DPR algorithms using synthetic data from TRMM/PR observations. IEEE J. Sel. Topics Appl. Earth Obs. Remote Sens., 7, 3931-3944, https:// doi.org/10.1109/JSTARS.2014.2320960.

Kulie, M. S., and L. Milani, 2018: Seasonal variability of shallow cumuliform snowfall: A CloudSat perspective. Quart. J. Roy. Meteor. Soc., 144, 329-343, https://doi.org/ 10.1002/qj.3222.

— — - N. B. Wood, S. Tushaus, R. Bennartz, and T. S. L'Ecuyer, 2016: A shallow cumuliform snowfall census using spaceborne radar. J. Hydrometeor., 17, 1261-1279, https://doi.org/10.1175/ JHM-D-15-0123.1.

Kummerow, C., W. Barnes, T. Kozu, J. Shiue, and J. Simpson, 1998: The Tropical Rainfall Measuring Mission (TRMM) sensor package. J. Atmos. Oceanic Technol., 15, 809-816, https://doi.org/ 10.1175/1520-0426(1998)015<0809:TTRMMT>2.0.CO;2.

Lebsock, M. D., and T. S. L'Ecuyer, 2011: The retrieval of warm rain from CloudSat. J. Geophys. Res., 116, D20209, https:// doi.org/10.1029/2011JD016076.

Leon, D. C., Z. Wang, and D. Liu, 2008: Climatology of drizzle in marine boundary layer clouds based on 1 year of data from CloudSat and Cloud-Aerosol Lidar and Infrared Pathfinder Satellite Observations (CALIPSO).
J. Geophys. Res., 113, D00A14, https://doi.org/10.1029/ 2008JD009835.

Lietzke, C. E., C. Deser, and T. H. Vonder Harr, 2001: Evolutionary structure of the eastern Pacific double ITCZ based on satellite moisture profile retrievals. J. Climate, 14, 743-751, https://doi.org/10.1175/1520-0442(2001)014<0743: ESOTEP $>2.0 . \mathrm{CO} ; 2$.

Liu, C., 2011: Rainfall contributions from precipitation systems with different sizes, convective intensities, and durations over the tropics and subtropics. J. Hydrometeor., 12, 392-412, https://doi.org/10.1175/2010JHM1320.1.

Liu, G., 2004: Approximation of single scattering properties of ice and snow particles for high microwave frequencies. J. Atmos. Sci., 61, 2441-2456, https://doi.org/10.1175/1520-0469(2004) $061<2441$ :AOSSPO $>2.0 . \mathrm{CO} ; 2$.

Mace, G. G., and S. Avey, 2017: Seasonal variability of warm boundary layer cloud and precipitation properties in the Southern Ocean as diagnosed form A-Train data. J. Geophys. Res. Atmos., 122, 1015-1032, https://doi.org/10.1002/ 2016JD025348.

Munchak, S. J., C. D. Kummerow, and G. Elsaesser, 2012: Relationships between the raindrop size distribution and properties of the environment and clouds inferred from TRMM. J. Climate, 25, 2963-2978, https://doi.org/10.1175/ JCLI-D-11-00274.1.

Seto, S., T. Iguchi, and T. Oki, 2013: The basic performance of a precipitation retrieval algorithm for the Global Precipitation Measurement Mission's single/dual-frequency radar measurements. IEEE Trans. Geosci. Remote Sens., 51, 5239-5251, https://doi.org/10.1109/TGRS.2012.2231686.

Shige, S., T. Watanabe, H. Sasaki, T. Kubota, S. Kida, and K. Okamoto, 2008: Validation of western and eastern Pacific rainfall estimates from the TRMM PR using a radiative transfer model. J. Geophys. Res., 113, D15116, https://doi.org/ 10.1029/2007JD009002.

Skofronick-Jackson, G., and Coauthors, 2017: The Global Precipitation Measurement (GPM) mission for science and society. Bull. Amer. Meteor. Soc., 98, 1679-1695, https:// doi.org/10.1175/BAMS-D-15-00306.1.

Smalley, M., T. L'Ecuyer, M. Lebsock, and J. Haynes, 2014: A comparison of precipitation occurrence from the NCEP Stage IV QPE product and the CloudSat Cloud Profiling Radar. J. Hydrometeor., 15, 444-458, https://doi.org/10.1175/ JHM-D-13-048.1.

Stephens, G. L., and Coauthors, 2008: The CloudSat mission: Performance and early science after the first year of operation. J. Geophys. Res., 113, D00A18, https://doi.org/10.1029/ 2008JD009982.

_ , and Coauthors, 2010: Dreary state of precipitation in global models. J. Geophys. Res., 115, D24211, https://doi.org/10.1029/ 2010JD014532.

Wood, N. B., T. S. L'Ecuyer, D. G. Vane, G. L. Stephens, and P. Partain, 2013a: Level 2C snow profile process description and interface control document. JPL Doc., 21 pp., http://www. cloudsat.cira.colostate.edu/sites/default/files/products/files/2CSNOW-PROFILE_PDICD.P_R04.20130210.pdf.

F. L. Bliven, and G. L. Stephens, 2013b: Characterization of video disdrometer uncertainties and impacts on estimates of snowfall rate and radar reflectivity. Atmos. Meas. Tech., 6, 3635-3648, https://doi.org/10.5194/amt-6-3635-2013.

- ——, A. J. Heymsfield, G. L. Stephens, D. R. Hudak, and P. Rodriguez, 2014: Estimating snow microphysical properties using collocated multisensor observations. 
J. Geophys. Res. Atmos., 119, 8941-8961, https://doi.org/ 10.1002/2013JD021303.

Wood, R., 2012: Stratocumulus clouds. Mon. Wea. Rev., 140, 2373-2423, https://doi.org/10.1175/MWR-D-11-00121.1.

Xie, P., and P. A. Arkin, 1997: Global precipitation: A 17-year monthly analysis based on gauge observations, satellite estimates, and numerical model outputs. Bull. Amer. Meteor. Soc., 78, 2539-2558, https://doi.org/10.1175/1520-0477(1997) 078<2539:GPAYMA $>2.0 . \mathrm{CO} ; 2$.
Yum, S. S., and J. G. Hudson, 2004: Wintertime/summertime contrasts of cloud condensation nuclei and cloud microphysics over the southern ocean. J. Geophys. Res., 109, D06204, https://doi.org/10.1029/2003JD003864.

Zuidema, P., J. Redemann, J. Haywood, R. Wood, S. Piketh, M. Hipondoka, and P. Formenti, 2016: Smoke and clouds above the Southeast Atlantic: Upcoming field campaigns probe absorbing aerosol's impact on climate. Bull. Amer. Meteor. Soc., 97, 1131-1135, https://doi.org/10.1175/BAMS-D-15-00082.1. 